\title{
Optimal Operational Decision Making of Manufacturers and Authorized Remanufacturers with Patent Licensing under Carbon Cap-and-Trade Regulations
}

\author{
Biyu Liu, ${ }^{1,2,3}$ Zhongsheng Hua, ${ }^{1}$ Qinhong Zhang, ${ }^{4}$ Haidong Yang $\mathbb{D},{ }^{2,3}$ \\ and Athanasios Migdalas ${ }^{3}$ \\ ${ }^{1}$ School of Management, Zhejiang University, Hangzhou 310058, China \\ ${ }^{2}$ School of Economics and Management, Fuzhou University, Fuzhou 350116, China \\ ${ }^{3}$ Industrial Logistics, Luleå University of Technology, Luleå 97187, Sweden \\ ${ }^{4}$ Sino-US Global Logistics Institute, Shanghai Jiao Tong University, Shanghai 200030, China \\ Correspondence should be addressed to Haidong Yang; yanghd428@gmail.com
}

Received 20 April 2020; Revised 9 June 2020; Accepted 17 June 2020; Published 22 July 2020

Guest Editor: Tingqiang Chen

Copyright $\odot 2020$ Biyu Liu et al. This is an open access article distributed under the Creative Commons Attribution License, which permits unrestricted use, distribution, and reproduction in any medium, provided the original work is properly cited.

Constrained by production capacity and the pressure to reduce emissions, many original equipment manufacturers (OEMs) authorize third-party remanufacturers (TPRs) to remanufacture patented products. We investigate the operational decisions of OEMs and authorized TPRs under carbon cap-and-trade regulations in a two-echelon supply chain. We first formulate an operational decision model for OEMs before a TPR enters. Then, for the cases of centralized and decentralized decision making, we formulate an operational decision-making model for the TPR and, subsequently, establish one for the OEM after the TPR enters. We further analyze the effects of carbon emissions cap, trading price of carbon permits, yield rate, and consumer willingness to pay (WTP) on optimal decisions. Our results indicate: whether TPRs accept authorization remanufacturing depending on the ratio of carbon emissions cap to carbon emissions for producing per remanufactured product; royalty rate is negatively affected by trading price of carbon permits and per remanufactured product' carbon emissions other than that for per new product, and can offset the threat caused by TPRs; the implementation of carbon cap-and-trade regulations causes OEMs to charge TPRs lower royalty rate; centralized decision making increases the total profit of the supply chain and delivers superior environmental benefits. As yield rate and WTP increase, the total profit increases, increasingly sensitive to WTP.

\section{Introduction}

Environmental pollution has received significant attention in the past few decades and many countries have implemented various carbon emission regulations, such as carbon cap-and-trade, carbon emission taxes, and carbon offsets, to reduce carbon emissions [1]. According to data gathered for the Product Carbon Footprint (PCF) pilot project in Germany, production in manufacturing industry generates inordinate amounts of carbon emissions [2].

Remanufacturing has been conceived as a significant strategy to achieve energy conservation and emissions reduction $[3,4]$. According to Jiang et al. [5], remanufacturing can decrease air pollutants by over $80 \%$ compared to manufacturing. Similarly, Smith and Keoleian [6] signify that, in the United States, remanufacturing of automobile engines decreases energy consumption by $68 \%-83 \%$ and reduces carbon emissions by $73 \%-87 \%$. The importance of remanufacturing is further evident in the large number of end-of-life (EOL) vehicles, which will presumably exceed 100 million by 2020 [7].

The large volume of used products, however, poses a great challenge to OEMs' capacity; with the result that OEMs typically authorize third-party remanufacturers (TPRs), we also call it as authorized remanufacturers to undertake remanufacturing activities and resell the remanufactured 
products without involving the OEMs [8]. In recent years, such practices have developed in some countries [9]. For example, in 2010, China's National Development and Reform Commission (CNDRC) announced that the Chinese government focused specifically on developing the remanufacturing industry (China Remanufacturing, 2015). By 2013, CNDRC approved 28 remanufacturers, a majority of them being TPRs, who were operating as authorized remanufacturers (National Development and Reform Commission, 2015). In particular, Apple signed an agreement with Foxconn in 2015, under which Foxconn was authorized to remanufacture EOL iPhones and resell them in Chinese market [10].

Although authorized remanufacturing can greatly reduce carbon emissions, it also inevitably results in a competition threat to OEMs (e.g., [11]). OEMs must balance the goal of emissions reduction and the problem of demand competition caused by authorized remanufacturing under carbon emission regulations. Furthermore, TPRs must clarify the effects of regulations on their decisions and respond to remanufacturing authorization with optimal decision making. Thus, we address the following problems: what is the condition that TPRs accept authorization? What is the optimal royalty rate that OEMs charge TPRs to satisfy both parties? How do carbon emission regulations affect the optimal decisions of OEMs and TPRs? Should OEMs decrease the production quantity and sales price after TPRs enter? Would their profit level be significantly affected with the constraint of carbon emission regulations? To the best of our knowledge, few studies have addressed these issues. Given that more than 20 countries and regions globally have adopted cap-and-trade regulations [12], we examine the optimal operational decisions of OEMs and TPRs under this regulation. In particular, we first propose an optimal production and pricing decision-making model to address an OEM's decision problem before a TPR enters. Then, for the cases of centralized and decentralized decision making, we formulate an operational decision-making model for the TPR and, subsequently, establish one for the OEM after the TPR enters. We also compare the differences between these decision-making approaches. Finally, we investigate how the optimal decisions for the OEM and TPR change with respect to the carbon emission cap, the trading price of carbon permits, yield rate, and the consumer willingness to pay (WTP).

The remainder of this paper is organized as follows. Section 2 reviews the associated literature. Section 3 describes the problem, and in Section 4, we formulate the aforementioned models to derive the optimal decisions for OEMs and TPRs under carbon cap-and-trade regulations. Section 5 discusses the results and presents a sensitivity analysis with numerical examples. We conclude our study and propose future research in Section 6. All proofs are provided in the Appendix.

\section{Literature Review}

Our study covers three important streams in the literature: demand competition between new and remanufactured products, authorized remanufacturing, and operational decision making of OEMs and TPRs under carbon emission regulations.

Demand competition in new and remanufactured products has been investigated extensively. Some scholars studied the competition from the perspective of OEMs $[13,14]$. Some scholars extend this case to consider both OEMs and TPRs. They investigated the competition in production quantity, service, and price (e.g., $[3,8,15,16]$ ). Several papers also researched the competition between OEMs and TPRs but in different settings. For example, Mitra and Webster [17] formulated a two-period model to explore government subsidies' effect on remanufacturing when an OEM competes with a TPR. Wu [18] studied the competition between OEMs and TPRs in recycling and sales markets by building a closed-loop supply chain (CLSC) model. Zhu et al. [19] considered a duopoly with competition in the sales of new products in trade-ins markets within a two-period planning horizon. Hong et al. [20] discussed the quantity competition between an OEM and a TPR with technology licensing in the reverse channel of a CLSC. Ho et al. [21, 22] investigated the effects of green consumers' purchase behaviors on demand and price by contemplating both internal and external competition. Zhou and Gupta [23] studied the life cycle pricing strategies based on the different generations of new and remanufactured products. Some scholars introduced warranty policy as a competition to remanufactured products. For example, based on this policy, Liao [24] proposed a newsvendor model to capture the remanufacturing system's features. Liu et al. [25] identified the conditions of the optimal pricing and production strategies on new and remanufactured products considering a nonrenewing free replacement warranty. Sun et al. [26] analyzed the differentiation competition between OEM and TPR owning to customers' different sensitive points on new and remanufactured products. These studies, however, do not provide a comprehensive discussion with regard to such competition in light of the effects of carbon emission regulations.

Compared to competition in remanufacturing, authorized remanufacturing has received less attention in the literature. As regards the difference between outsourcing and authorized remanufacturing, Zou et al. [10] compared the two by formulating a game model between an OEM and a TPR and signified that TPRs prefer the authorization approach when consumers perceive remanufactured products with less value. Zhang et al. [27] and Zhang et al. [28] investigated the strategy implications of authorization between two firms in a differentiated Stackelberg framework when the innovator faces uncertain research and development outcomes. Other studies have explored ways in which the OEMs charge royalty fees for authorized remanufacturing. Hashiguchi [29] proposed that TPRs purchasing licenses from OEMs are immune from allegations of patent infringement. In most authorized remanufacturing operations, OEMs charge TPRs royalty fees. Abdulrahman et al. [4] suggested that OEMs should charge TPRs more royalty fees so that they could achieve efficient allocation of the excess benefits generated by remanufacturing. Huang and 
Wang [30] proved a robust region for the royalty fee and production decisions with the context of demand disruptions. Our literature review indicates that a few studies have examined the decisions of OEMs and TPRs regarding authorized remanufacturing. The following studies investigated authorized remanufacturing from different aspects. Oraiopoulos et al. [31] examined an OEM's decisions on optimal royalty fee when a TPR undertook remanufacturing activities. Based on this study, Hong et al. [20] investigated the optimal collection and remanufacturing decisions by considering competition not only in the forward channel but also in the reverse one. Further, Zhang et al. [32] studied the same decisions but combing with government policy, and Huang and Wang [33] analyzed the effects of strategic consumer behavior on different remanufacturing scenarios. Considering different authorized members, Zhao et al. [34] developed the operational decision models of OEMs and retailers with two cases, one of which the OEMs remanufacture and the other is to authorize remanufacturing to the retailers. However, they did not consider the effects of carbon emission regulations. In practice, regulations affect the decision making of the OEMs and the authorized remanufacturers because of the different carbon emissions generated when producing new products as opposed to remanufacturing products.

Studies addressing operational issues in manufacturing under carbon emission regulations are numerous (e.g., $[27,35])$ but less in the case of remanufacturing. One study [36] noted that carbon emission regulations create carbon costs and hence complicate production decisions regarding new and remanufactured products. Some scholars discussed the optimal production decisions on manufacturing and remanufacturing under carbon tax policy. Combing with government subsidy policy, Cao et al. [37] studied the optimal production and pricing decisions in a dual-channel supply chain. Cao et al. [38] further investigated the optimal warranty period and trade-in strategies for new and remanufactured products by considering the trade-in subsidies policy. To the best of our knowledge, there are only a few papers that have covered remanufacturing decisions considering cap-and-trade regulations that are most closely related to this study. By considering independent and substitutable demand markets under carbon cap-andtrade regulations, Chang et al. [39] presented optimal production decisions for a manufacturer who produces both new and remanufactured products. The results indicate that regulations greatly influence the production decisions in manufacturing and remanufacturing. Similar to this study, Wang et al. [40] examined a capital-constrained OEM's production decisions with a downward substitution strategy under cap-and-trade regulations and found that a carbon emission constraint always encourages the OEM to generate more remanufactured products. By considering trade-ins for remanufactured products, Miao et al. [41] derived the optimal pricing and production decisions under cap-and-trade regulations. Zhang et al. $[32,42]$ further introduced green innovation into a hybrid manufacturing and remanufacturing system and examined the joint pricing strategies and green innovation policy.
Their results indicate that carbon emission regulations can increase sales of remanufactured products while decreasing the demand for new products. A few papers further investigated the effects of carbon emission regulations' parameters on remanufacturing decisions. Liu et al. [43] investigated the optimal production decisions of an independent remanufacturer under cap-and-trade regulations and compared the results to those under other regulations. The results indicate that a higher carbon emission cap would be better for promoting the development of remanufacturers. Shu et al. [44] investigated the impact of a carbon emissions quota and its trade prices on remanufacturing decisions and provided some insights for governments and firms in terms of carbon permits allocation. Owning to the variation of the tax price, Dou et al. [45] analyzed the effects of the tax price on the production planning of manufacturing and remanufacturing. However, the aforementioned papers only consider the effects of carbon cap-and-trade regulations in settings without authorized remanufacturing. In fact, under authorized remanufacturing, carbon emission regulations exert different effects on the decision making of the OEMs and the TPRs.

In summary, our study is different from extant research as follows. First, we investigate the condition that TPRs accept authorization under cap-and-trade regulations; second, we examine the effects of cap-and-trade regulations on the decision making of OEMs and authorized TPRs with patent licensing. Presently, the literature only covers the effects of authorized remanufacturing without this constraint; third, we specify the effects of yield rate and consumer WTP on the decision making of OEMs and TPRs. To the best of our knowledge, our study is the first to address the above issues with the consideration of both authorized remanufacturing and carbon cap-and-trade regulations.

\section{Problem Description}

We consider a supply chain comprising an OEM and a TPR, in which the OEM manufactures new products and authorizes the TPR to undertake acquisition and remanufacturing. To analyze the effects of the TPR on the OEM, we discuss two scenarios. In scenario 1, the OEM sells new products as a monopolist without remanufacturing; in scenario 2, the OEM still sells new products while facing competition from the TPR.

Throughout the paper, we let the subscripts $m$ and $r$ denote the OEM and the TPR, respectively. The notations used in the model are listed in Table 1.

According to Ferguson and Toktay [13], the relationship between demand and price for new and remanufactured products can be described as follows.

In scenario 1, since remanufacturing does not occur, we have

$$
p_{1 m}=A-q_{1 m}
$$

where $A$ is assumed to be the same for the two scenarios, that is, market expansion and contraction are not considered in this study. 
TABle 1: Notation.

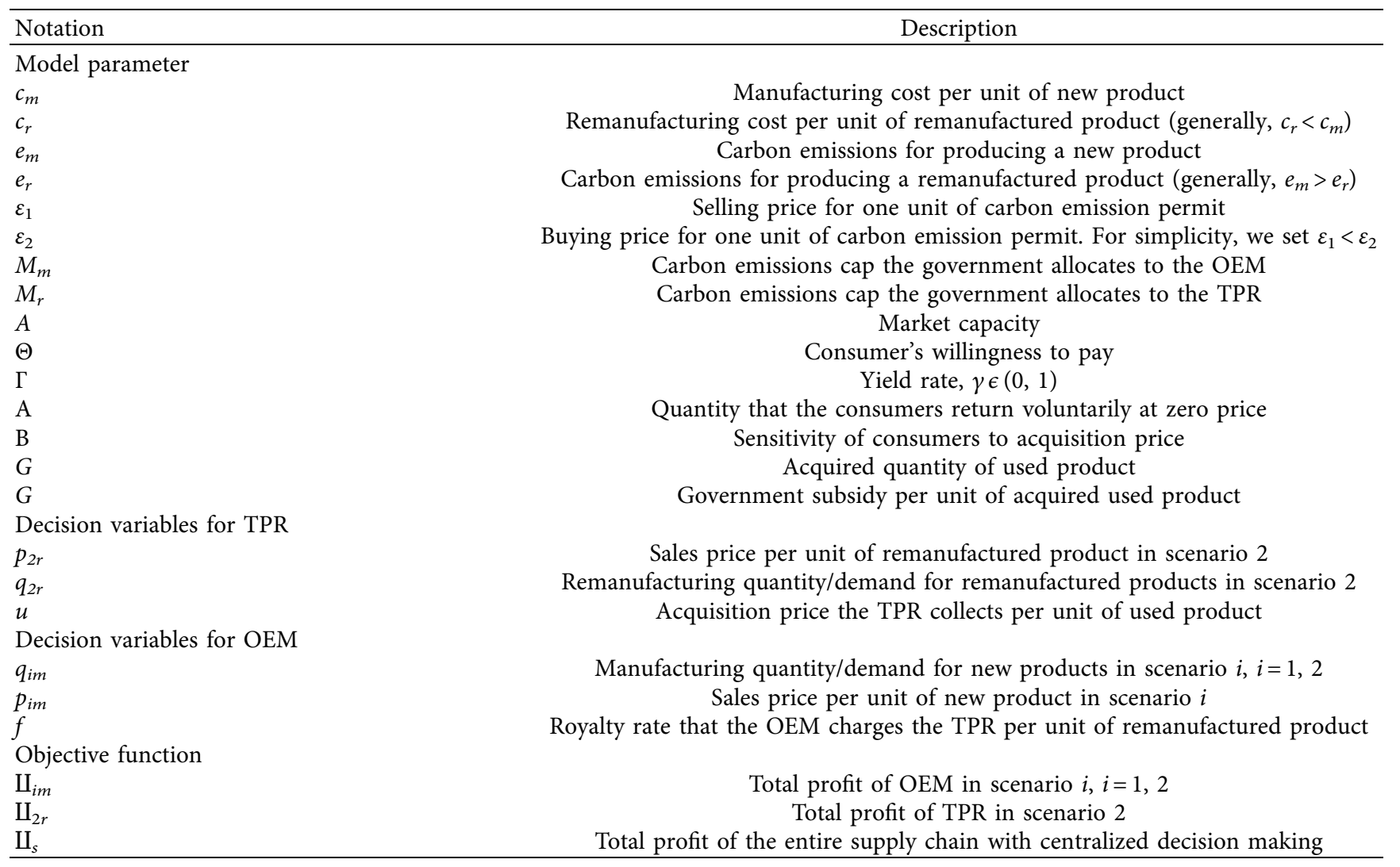

In scenario 2 , the OEM only produces new products and the TPR makes remanufactured products. The collected used products are remanufactured with yield rate $\gamma$, that is,

$$
q_{2 r}=y G(u)
$$

with $G(u)=\alpha+\beta u$, where $\alpha$ indicates consumer environmental consciousness and $\beta$ indicates the influence of unit acquisition price on the acquired quantity.

Then, we have the following inverse demand functions:

$$
\begin{aligned}
& p_{2 m}=A=q_{2 m}-\theta q_{2 r}, \\
& p_{2 r}=\theta\left(A-q_{2 m}-q_{2 r}\right),
\end{aligned}
$$

where if $\theta=0$, consumers are only willing to pay new products; if $\theta=1$, consumers are willing to pay the same for new or remanufactured products. As the majority of consumers are eclectic, we assume $0<\theta<1$.

\section{Model Formulation and Solution}

We first establish a production and pricing decision-making model for the OEM under cap-and-trade regulations in scenario 1 . Then, in scenario 2 , for the cases of centralized and decentralized decision making, we formulate an operational decision-making model for the TPR and, subsequently, establish one for the OEM.

In scenario 1 , since the OEM only produces new products, the OEM's profit can be described as

$$
\begin{aligned}
\prod_{1 m}= & q_{1 m}\left(p_{1 m}-c_{m}\right)+\varepsilon_{1}\left(M_{m}-q_{1 m} e_{m}\right)^{+} \\
& -\varepsilon_{2}\left(q_{1 m} e_{m}-M_{m}\right)^{+},
\end{aligned}
$$

where $(a-b)^{+}$means $\max \{a-b, 0\}$. Hence, we have

$$
\prod_{1 m}= \begin{cases}q_{1 m}\left(p_{1 m}-c_{m}\right)-\varepsilon_{2}\left(q_{1 m} e_{m}-M_{m}\right), & M_{m} \leq q_{1 m} e_{m} \\ q_{1 m}\left(p_{1 m}-c_{m}\right)+\varepsilon_{1}\left(M_{m}-q_{1 m} e_{m}\right), & \text { otherwise. }\end{cases}
$$

In scenario 2, the profits of the OEM and the TPR, respectively, are

$$
\begin{aligned}
\prod_{2 m}= & q_{2 m}\left(p_{2 m}-c_{m}\right)+q_{2 r} f+\varepsilon_{1}\left(M_{m}-q_{2 m} e_{m}\right)^{+} \\
& -\varepsilon_{2}\left(q_{2 m} e_{m}-M_{m}\right)^{+}, \\
\prod_{2 r}= & q_{2 r}\left(p_{2 r}-c_{r}-f\right)+G(u)(g-u) \\
& +\varepsilon_{1}\left(M_{r}-q_{2 r} e_{r}\right)^{+}-\varepsilon_{2}\left(q_{2 r} e_{r}-M_{r}\right)^{+} .
\end{aligned}
$$

4.1. OEM's Production and Pricing Decision Making in Scenario 1. As mentioned above, in scenario 1, all the market demand is satisfied by the OEM's new products. We can, therefore, easily derive the optimal solutions as Proposition 1. 
Proposition 1. In scenario 1, the optimal production quantity $q_{1 m}^{*}$ and the optimal sales price $p_{1 m}^{*}$ for new products, respectively, are as follows:

$$
\begin{aligned}
& q_{1 m}^{*}= \begin{cases}M_{m} / e_{m}, & q_{1 m}^{\prime \prime} \leq M_{m} / e_{m} \leq q_{1 m}^{\prime}, \\
\left(A-c_{m}-B\right) / 2, & \text { otherwise, }\end{cases} \\
& p_{1 m}^{*}= \begin{cases}A-M_{m} / e_{m}, & q_{1 m}^{\prime \prime} \leq M_{m} / e_{m} \leq q_{1 m}^{\prime}, \\
\left(A+c_{m}+B\right) / 2, & \text { otherwise, }\end{cases}
\end{aligned}
$$

where $q_{1 m}^{\prime}=\left(A-c_{m}-\varepsilon_{1} e_{m}\right) / 2$; it means the OEM's manufacturing quantity, which maximizes the profits, when the government allocates the OEM enough carbon emission permits. $q_{1 m}^{\prime \prime}=\left(A-c_{m}-\varepsilon_{2} e_{m}\right) / 2$; it means the OEM's manufacturing quantity, which maximizes the profits when the carbon emission permits allocated by government are not enough for the OEM to manufacture new products.

$$
B= \begin{cases}\varepsilon_{1} e_{m}, & M_{m} / e_{m}>q_{1 m}^{\prime}, \\ \varepsilon_{2} e_{m}, & M_{m} / e_{m}<q_{1 m}^{\prime \prime} .\end{cases}
$$

Thus, the corresponding profit is

$$
\begin{aligned}
\prod_{1 m}^{*}= & q_{1 m}^{*}\left(p_{1 m}^{*}-c_{m}\right)+\varepsilon_{1}\left(M_{m}-q_{1 m}^{*} e_{m}\right)^{+} \\
& -\varepsilon_{2}\left(q_{1 m}^{*} e_{m}-M_{m}\right)^{+} .
\end{aligned}
$$

The proof is provided in Appendix A.

In order to analyze the relationship between $M_{m} / e_{m}$ and the optimal manufacturing quantity, we define $M_{m} / e_{m}$ as the virtual manufacturing quantity. The carbon emissions generated by manufacturing these new products exactly equal the carbon emissions quota from the government.

As shown in Proposition 1, the value of $M_{m} / e_{m}$ affects the optimal decisions of the OEM in scenario 1 . When the virtual manufacturing quantity is between $q_{1 m}^{\prime}$ and $q_{1 m}^{\prime}$, the optimal manufacturing quantity equals the virtual manufacturing quantity, which is not affected by the trading price. The reason is if the OEM manufactures less than the virtual manufacturing quantity, the savings on marginal cost from reducing a unit new product are less than the loss in marginal revenue; if the OEM manufactures more than the virtual manufacturing quantity, the marginal revenue from increasing a unit new product is less than the marginal cost. Therefore, in this case, the optimal quantity decision for the OEM should be $M_{m} / e_{m}$. This generally occurs when carbon emission permits are traded at a low selling price but a high buying price. Otherwise, the optimal manufacturing quantity is negatively related to the trading price. The OEM can pursue profit maximization by setting different sales prices for new products and adjusting production strategies based on the trading price of carbon permits.

4.2. Decision Making of the OEM and TPR in Scenario 2. In scenario 2, the OEM only produces new products, and the TPR remanufactures the acquired used products with the OEM's authorization.

4.2.1. Decentralized Decision Making. After the TPR enters, competition exists between the OEM and the TPR. We use a Stackelberg model to describe this competition. The OEM is the market leader, whereas the TPR is the follower. The Stackelberg game problem is solved through the backward method. First, we solve the TPR's optimal quantity/price of the remanufactured products under the condition that the decisions of the OEM are given. We then solve the OEM's optimal decisions after obtaining the TPR's optimal decisions. The optimal decisions can be summarized as Propositions 2 and 3.

Proposition 2. Given $q_{2 m}^{*}$, the strategies of the TPR are expressed as follows:

$$
\begin{aligned}
q_{2 r}^{*} & = \begin{cases}0, & q_{2 r}^{\prime} \leq M_{r} / e_{r} \leq q_{2 r}^{\prime}, \\
\frac{\gamma\left\{\beta \gamma\left[\theta\left(A-q_{2 m}^{*}\right)-c_{r}-f^{*}-C\right]+\beta g+\alpha\right\}}{2 \theta \beta \gamma^{2}+2}, & \text { otherwise, }\end{cases} \\
p_{2 r}^{*} & = \begin{cases}\text { random, } & q_{2 r}^{\prime} \leq M_{r} / e_{r} \leq q_{2 r}^{\prime}, \\
\frac{\theta\left\{\gamma\left[\beta \gamma\left(c_{r}+f^{*}+C\right)-\beta g-\alpha\right]+\left(\theta \beta \gamma^{2}+2\right)\left(A-q_{2 m}^{*}\right)\right\}}{2 \theta \beta \gamma^{2}+2}, & \text { otherwise, }\end{cases} \\
u^{*} & = \begin{cases}\text { random, } & q_{2 r}^{\prime} \leq M_{r} / e_{r} \leq q_{2 r}^{\prime}, \\
\frac{\beta \gamma\left[\theta\left(A-q_{2 m}^{*}-2 \alpha \gamma\right)-c_{r}-f^{*}-C\right]+\beta g-\alpha}{2 \theta \beta^{2} \gamma^{2}+2 \beta}, & \text { otherwise, }\end{cases} \\
G^{*}\left(u^{*}\right)=\alpha+\beta u^{*}, & \\
\prod_{2 r}^{*}= & q_{2 r}^{*}\left(p_{2 r}^{*}-c_{r}-f^{*}\right)+G\left(u^{*}\right)\left(g-u^{*}\right)+\varepsilon_{1}\left(M_{r}-q_{2 r}^{*} e_{r}\right)^{+}-\varepsilon_{2}\left(q_{2 r}^{*} e_{r}-M_{r}\right)^{+},
\end{aligned}
$$


where $q_{2 r}^{*}, p_{2 r}^{*}, u^{*}$, and $G^{*}\left(u^{*}\right)$ are the TPR's optimal decisions on remanufacturing quantity, sales price of remanufactured products, acquisition price, and quantity of the used products, respectively; $q_{2 m}^{*}$ and $f^{*}$ are the OEM's optimal decisions on manufacturing quantity and royalty rate; $\prod_{2 r}^{*}$ is the corresponding profit; $q_{2 r}$ represents the TPR's remanufacturing quantity, which maximizes the profits when the government allocates the TPR enough carbon emission permits; and $q_{2 r}$ represents the TPR's remanufacturing quantity, which maximizes the profits when the carbon emission permits allocated by the government are not enough for the TPR to remanufacture collected used products.

$$
\begin{gathered}
\left\{\begin{array}{l}
q_{2 r}^{\prime}=\left\{\beta \gamma^{2}\left[\theta\left(A-q_{2 m}^{*}\right)-\varepsilon_{1} e_{r}-c_{r}-f^{*}\right]+\beta \gamma g+\alpha \gamma\right\} /\left(2 \theta \beta \gamma^{2}+2\right), \\
q_{2 r}^{\prime}=\left\{\beta \gamma^{2}\left[\theta\left(A-q_{2 m}^{*}\right)-\varepsilon_{2} e_{r}-c_{r}-f^{*}\right]+\beta \gamma g+\alpha \gamma\right\} /\left(2 \theta \beta \gamma^{2}+2\right),
\end{array}\right. \\
C= \begin{cases}\varepsilon_{1} e_{r}, & M_{r} / e_{r}>q_{2 r}, \\
\varepsilon_{2} e_{r}, & q_{2 r}^{\prime}>M_{r} / e_{r} .\end{cases}
\end{gathered}
$$

The proof is provided in Appendix B.

In order to analyze the relationship between $M_{r} / e_{r}$ and the optimal remanufacturing quantity, we define $M_{r} / e_{r}$ as the virtual remanufacturing quantity based on $M_{r}$ similar to scenario 1.

From Proposition 2, the following conclusions can be drawn.

The virtual remanufacturing quantity affects the optimal operational decisions of the TPR. When the virtual remanufacturing quantity is between $q_{2 r}^{\prime}$ and $q_{2 r}^{\prime}$, the TPR would not accept authorization from the OEM. In this case, if the TPR does not consider the OEM's decision, the optimal remanufacturing quantity should be $M_{r} / e_{r}$. But if $q_{2 r}^{*}=M_{r} / e_{r}$, the profit of the OEM increases monotonously vs. royalty rate $f$, for which the TPR's best choose is to refuse authorization. Otherwise, the optimal decisions of the TPR are related to the trading price of carbon emission permits. The remanufacturing quantity, acquisition price, and acquisition quantity of used products are negatively affected by the trading price of carbon emission permits $\left(\varepsilon_{1}\right.$ or $\left.\varepsilon_{2}\right)$; however, the sales price of remanufactured products is positively affected.

Proposition 3. Given the TPR's pricing strategies, the OEM's strategies are as follows: when $q_{2 r}^{*}=M_{r} / e_{r} \leq q_{2 r}, q_{2 m}^{*}$ are as the same as in scenario 1; otherwise,

$$
\begin{aligned}
q_{2 m}^{*} & = \begin{cases}M_{m} / e_{m}, & q_{2 m}^{\prime} \leq M_{m} / e_{m} \leq q_{2 m}^{\prime}, \\
\frac{2\left(A-c_{m}\right)\left(\theta \beta \gamma^{2}+1\right)+\theta \gamma\left[\beta \gamma\left(c_{r}-\theta A+C\right)-\beta g-\alpha\right]-2\left(\theta \beta \gamma^{2}+1\right) D}{4 \theta \beta \gamma^{2}-2 \theta^{2} \beta \gamma^{2}+4}, & \text { otherwise, }\end{cases} \\
f^{*} & =\frac{\beta \gamma\left(\theta A-c_{r}-C\right)+\beta g+\alpha}{2 \beta \gamma}, \\
p_{2 m}^{*} & =A-q_{2 m}^{*}-\theta q_{2 r}^{*}, \\
\prod_{2 m}^{*} & =q_{2 m}^{*}\left(p_{2 m}^{*}-c_{m}\right)+q_{2 r}^{*} f^{*}+\varepsilon_{1}\left(M_{m}-q_{2 m}^{*} e_{m}\right)^{+}-\varepsilon_{2}\left(q_{2 m}^{*} e_{m}-M_{m}\right)^{+},
\end{aligned}
$$

where $q_{2 m}^{*}, f^{*}$, and $p_{2 m}^{*}$ are the OEM's optimal decisions on manufacturing quantity, royalty rate, and sales price of new products, respectively; $\prod_{2 m}^{*}$ is the corresponding profit; $q_{2 m}^{\prime}$ represents the OEM's manufacturing quantity to maximize its profits when the government allocates it enough carbon emission permits; and $q_{2 m}^{\prime \prime}$ represents the OEM's manufacturing quantity to maximize its profits when the carbon emission permits allocated by the government are not enough for the OEM to manufacture new products. 


$$
\begin{aligned}
& \left\{\begin{array}{l}
\dot{q}_{2 m}^{\prime}=\frac{2\left(A-c_{m}\right)\left(\theta \beta \gamma^{2}+1\right)+\theta \gamma\left[\beta \gamma\left(c_{r}-\theta A\right)-\beta g-\alpha+C\right]-2\left(\theta \beta \gamma^{2}+1\right) \varepsilon_{1} e_{m}}{4 \theta \beta \gamma^{2}-2 \theta^{2} \beta \gamma^{2}+4}, \\
q_{2 m}^{\prime}=\frac{2\left(A-c_{m}\right)\left(\theta \beta \gamma^{2}+1\right)+\theta \gamma\left[\beta \gamma\left(c_{r}-\theta A\right)-\beta g-\alpha+C\right]-2\left(\theta \beta \gamma^{2}+1\right) \varepsilon_{2} e_{m}}{4 \theta \beta \gamma^{2}-2 \theta^{2} \beta \gamma^{2}+4},
\end{array}\right. \\
& D= \begin{cases}\varepsilon_{1} e_{m}, & M_{m} / e_{m}>q_{2 m}^{\prime}, \\
\varepsilon_{2} e_{m}, & M_{m} / e_{m}<q_{2 m}^{\prime} .\end{cases}
\end{aligned}
$$

The proof is provided in Appendix C.

As defined in scenario 1 , we note $M_{m} / e_{m}$ as the virtual manufacturing quantity in scenario 2 . From Proposition 3 , we can conclude the following:

(1) When $M_{m} / e_{m}$ is between $\stackrel{\prime}{q_{2 m}}$ and $\dot{q}_{2 m}^{\prime}$, the optimal manufacturing quantity of the OEM should equal the virtual manufacturing quantity. This case is the same as in scenario 1, i.e., the TPR would not enter. Otherwise, the OEM's optimal decisions are related to the trading price and the carbon emissions generated per new and remanufactured product.

(2) The optimal royalty rate $\left(f^{*}\right)$ is negatively affected by the trading price of carbon emission permits $\left(\varepsilon_{1}\right.$ or $\varepsilon_{2}$ ). This result illustrates that the OEM charges the TPR a low royalty rate when the trading price is high. But even with a low royalty rate, the total royalty fee is not lower since remanufacturing quantity rises. Additionally, the optimal royalty rate is also related to carbon emissions per remanufactured product but is not affected by that of new product.

4.2.2. Centralized Decision Making. In this case, the OEM and the TPR make joint decisions to maximize the total profit of the entire supply chain. The total profit of the whole supply chain can be described as

$$
\begin{aligned}
\prod_{s}= & q_{2 m}\left(p_{2 m}-c_{m}\right)+q_{2 r}\left(p_{2 r}-c_{r}\right)+G(u)(g-u) \\
& +\varepsilon_{1}\left(M_{m}+M_{r}-q_{2 m} e_{m}-q_{2 r} e_{r}\right)^{+}-\varepsilon_{2} \\
& \cdot\left(q_{2 m} e_{m}+q_{2 r} e_{r}-M_{m}-M_{r}\right)^{+} .
\end{aligned}
$$

The optimal decisions are summarized as Proposition 4.

Proposition 4. With centralized decision making, the strategies of both parties are

$$
\begin{aligned}
q_{2 m}^{* *}= & \begin{cases}q_{2 m}^{c^{\prime \prime}}, & q_{2 m}^{c^{\prime \prime}} e_{m}+q_{2 r}^{c^{\prime \prime}} e_{r} \leq M_{m}+M_{r} \leq q_{2 m}^{c} e_{m}+q_{2 r}^{c} e_{r}, \\
\frac{A-c_{m}-B^{c}}{2}-\theta q_{2 r}^{* *}, & \text { otherwise, }\end{cases} \\
q_{2 r}^{* *}= & \begin{cases}q_{2 r}^{c^{\prime \prime}}, & q_{2 m}^{c^{\prime \prime}} e_{m}+q_{2 r}^{c^{\prime \prime}} e_{r} \leq M_{m}+M_{r} \leq q_{2 m}^{c} e_{m}+q_{2 r}^{c} e_{r}, \\
\frac{\gamma(\beta g+\alpha)+\beta \gamma^{2}\left(\theta c_{m}-c_{r}+C^{c}\right)}{2\left(\theta \beta \gamma^{2}-\theta^{2} \beta \gamma^{2}-1\right)}, & \text { otherwise, }\end{cases} \\
p_{2 m}^{* *}= & A-q_{2 m}^{* *}-\theta q_{2 r}^{* *}, \\
p_{2 r}^{* *}= & \theta\left(A-q_{2 m}^{* *}-q_{2 r}^{* *}\right), \\
u^{* *}= & \left(q_{2 r}^{* *}-\alpha \gamma\right) / \beta \gamma, \\
\prod_{s}^{* *}= & q_{2 m}^{* *}\left(p_{2 m}^{* *}-c_{m}\right)+q_{2 r}^{* *}\left(p_{2 r}^{* *}-c_{r}\right)+G(u)(g-u)+\varepsilon_{1}\left(M_{m}+M_{r}-q_{2 m}^{* *} e_{m}-q_{2 r}^{* *} e_{r}\right)^{+} \\
& -\varepsilon_{2}\left(q_{2 m}^{* *} e_{m}+q_{2 r}^{* *} e_{r}-M_{m}-M_{r}\right)^{+},
\end{aligned}
$$

where $q_{2 m}^{* *}$ and $p_{2 m}^{* *}$ are the OEM's optimal decisions on manufacturing quantity and sales price of new products, respectively; $q_{2 r}^{* *}, p_{2 r}^{* *}$, and $u^{* *}$ are the remanufacturer's optimal decisions on remanufacturing quantity, sales price of remanufactured products, and acquisition price of used products, respectively; $\prod^{s * *}$ is the corresponding total profit of the whole supply chain; and, 


$$
\begin{aligned}
& \left\{\begin{array}{l}
q_{2 m}^{c^{c}}=\frac{A-c_{m}-\varepsilon_{1} e_{m}}{2}-\theta q_{2 r}^{c}, \\
q_{2 m}^{c^{\prime \prime}}=\frac{A-c_{m}-\varepsilon_{2} e_{m}}{2}-\theta q_{2 r}^{c^{\prime \prime}}, \\
q_{2 m}^{c^{\prime \prime}}=\frac{M_{m}+M_{r}-e_{r} q_{2 r}^{c^{\prime \prime}}}{e_{m}}
\end{array}\right. \\
& \left\{\begin{array}{l}
q_{2 r}^{c^{\prime}}=\frac{\gamma(\beta g+\alpha)+\beta \gamma^{2}\left[\theta c_{m}-c_{r}+\varepsilon_{1}\left(\theta e_{m}-e_{r}\right)\right]}{2\left(\theta \beta \gamma^{2}-\theta^{2} \beta \gamma^{2}-1\right)}, \\
q_{2 r}^{c^{\prime \prime}}=\frac{\gamma(\beta g+\alpha)+\beta \gamma^{2}\left[\theta c_{m}-c_{r}+\varepsilon_{2}\left(\theta e_{m}-e_{r}\right)\right]}{2\left(\theta \beta \gamma^{2}-\theta^{2} \beta \gamma^{2}-1\right)}, \\
q_{2 r}^{c^{\prime \prime}}=\frac{\beta \gamma^{2}\left[2\left(M_{m}+M_{r}\right)\left(e_{r}-\theta e_{m}\right)-\left(A-c_{m}\right) e_{r} e_{m}\right]+e_{m}^{2} \gamma\left[\beta \gamma\left(\theta A-c_{r}\right)+(\beta g+\alpha)\right]}{2\left[\beta \gamma^{2}\left(e_{r}^{2}-2 \theta e_{r} e_{m}+\theta e_{m}^{2}\right)+e_{m}^{2}\right]},
\end{array}\right. \\
& B^{c}= \begin{cases}\varepsilon_{1} e_{m}, & M_{m}+M_{r}>q_{2 m}^{c} e_{m}+q_{2 r}^{c} e_{r}, \\
\varepsilon_{2} e_{m}, & M_{m}+M_{r}<q_{2 m}^{c^{\prime \prime}} e_{m}+q_{2 r}^{c^{\prime \prime}} e_{r},\end{cases} \\
& C^{c}= \begin{cases}\varepsilon_{1}\left(\theta e_{m}-e_{r}\right), & M_{m}+M_{r}>q_{2 m}^{c} e_{m}+q_{2 r}^{c} e_{r}, \\
\varepsilon_{2}\left(\theta e_{m}-e_{r}\right), & M_{m}+M_{r}<q_{2 m}^{c^{\prime \prime}} e_{m}+q_{2 r}^{c^{\prime \prime}} e_{r} .\end{cases}
\end{aligned}
$$

The proof is provided in Appendix D.

From Proposition 4, the following conclusions can be drawn:

(1) When the total carbon emission caps $\left(M_{m}+M_{r}\right)$ allocated to the OEM and the TPR are between $q_{2 m}^{c^{\prime \prime}} e_{m}+q_{2 r}^{c^{\prime \prime}} e_{r}$ and $q_{2 m}^{c} e_{m}+q_{2 r}^{c} e_{r}$, the decisions of the OEM and the TPR are not affected by the trading price but are related to carbon emissions caused by producing new and remanufactured product.

(2) When the total carbon emissions caps of the OEM and the TPR are less than $q_{2 m}^{c^{\prime \prime}} e_{m}+q_{2 r}^{c^{\prime}} e_{r}$ or more than $q_{2 m}^{c} e_{m}+q_{2 r}^{c} e_{r}$ and $\theta e_{m}>e_{r}$ holds, remanufactured products' sales price decreases, but remanufacturing quantity and acquisition price increase with the increase of $\varepsilon_{1}$ and $\varepsilon_{2}$. However, the sales price for new products increases, while manufacturing quantity decreases as $\varepsilon_{1}$ and $\varepsilon_{2}$ increases. When $\theta e_{m} \leq e_{r}$ the opposite occurs.

According to the above propositions, carbon emissions cap does affect the operational decisions of the OEM and the TPR and plays a great role in the TPR's decision on accepting authorization or not. Therefore, the government must set a reasonable carbon emissions cap for the OEMs and the TPRs. Conversely, based on their carbon emission caps and the trading price of carbon emission permits, the OEMs and TPRs must adjust their strategies in time to maximize their profits. In addition, WTP $(\theta)$ also affects the decisions. It is believed that producing a large number of remanufactured products while reducing the quantity of new products is economical, and therefore the total profit of the entire supply chain increases when $\theta$ is high. When the demand for remanufactured products increases, the TPR is compelled to collect an increasing number of used products to satisfy the demand. Thus, the environmental benefits also improve.

\section{Numerical Examples}

In this section, numerical examples are provided to examine the results of the comparison between the decisions before and after a TPR enters, under decentralization and centralization, and with or without the constraint of cap-andtrade regulations. As yield rate and WTP are also considerably affecting optimal decision making, we elaborate their effects in a series of figures. We set the base parameters to the following values: $A=1200, G(u)=20+4 u, c_{m}=300, e_{m}=1.5$, $c_{r}=150, \quad e_{r}=1, \quad g=1, \quad \gamma=0.9, \quad \theta=0.7, \quad \varepsilon_{1}=40, \quad \varepsilon_{2}=50$, $M_{m}=700$, and $M_{r}=10$.

5.1. Results of Optimal Decision Making. By substituting the parameter values into the solutions in Section 4, we obtain the optimal decisions in scenario 1 are as follows: $p_{1 m}^{*}=780$, $q_{1 m}^{*}=420$, and $\prod_{1 m}^{*}=216,400$. The results in scenario 2 are presented in Table 2 and 3.

Figure 1 presents the difference of the OEM's profit before and after the TPR enters (i.e., $\prod_{2 m}^{*}-\prod_{1 m}^{*}$, which we denote as $\Delta \prod_{m}$ ) with respect to yield rate. 
TABLE 2: The results in scenario 2 without a constraint on carbon emission regulations.

\begin{tabular}{|c|c|c|c|c|c|c|c|c|c|c|}
\hline Items & $p_{2 m}$ & $q_{2 m}$ & $p_{2 r}$ & $q_{2 r}$ & $f$ & $u$ & G & $\prod_{2 m}$ & $\prod_{2 r}$ & $\prod_{s}$ \\
\hline A & 750 & 434.72 & 520.42 & 21.83 & 348.33 & 1.06 & 24.25 & $203,227.51$ & 480.46 & $203,707.97$ \\
\hline B & 750 & 405.01 & 511.50 & 64.27 & - & 12.85 & 71.41 & - & - & $204,642.35$ \\
\hline
\end{tabular}

Note. A-decentralized decision making; B-centralized decision making.

TABLE 3: The results in scenario 2 with cap-and-trade regulations.

\begin{tabular}{|c|c|c|c|c|c|c|c|c|c|c|}
\hline Items & $p_{2 m}$ & $q_{2 m}$ & $p_{2 r}$ & $q_{2 r}$ & $f$ & $u$ & G & $\prod_{2 m}$ & $\prod_{2 r}$ & $\prod_{s}$ \\
\hline A & 780 & 404.26 & 541.28 & 22.48 & 328.33 & 1.24 & 24.98 & $217,171.81$ & $12,509.72$ & $229,681.53$ \\
\hline B & 780 & 373.66 & 532.10 & 66.20 & - & 13.39 & 73.55 & - & - & $230,672.82$ \\
\hline
\end{tabular}

Note. A-decentralized decision making; B-centralized decision making.

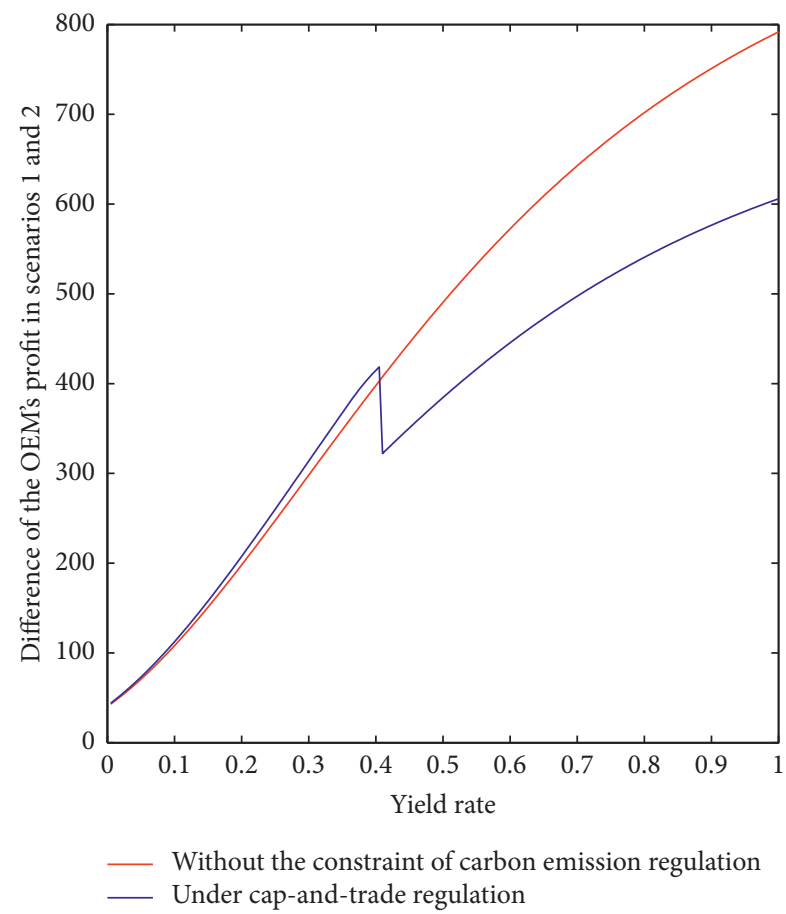

FIgURE 1: Difference in the OEM's profit before and after the TPR enters vs. yield rate.

It can be observed from Figure 1 that overall, the difference increases as yield rate increases. There exists an inflection point; however, under cap-and-trade regulations, the difference declines precipitously when yield rate is approximately 0.4 . This inflection point occurs when the total carbon emissions are equal to the cap. Afterwards, the difference still increases.

5.2. Effects of Yield Rate on Optimal Decision Making. In this section, we set $\theta=0.7$ and plot Figures $2-7$ to illustrate the effects of yield rate. We denote Case 1 and Case 2 as decentralized decision making without or with a constraint of cap-and-trade regulations and Case 3 and Case 4 as centralized decision making without or with a constraint of cap-and-trade regulations, respectively.
We conclude the following based on Figure 2. (1) As yield rate increases, the demand for new products decreases, whereas the demand for remanufactured products increases in all four cases, which are in accord with the propositions in Section 4. (2) Compared to decentralized decision making, the effects of the yield rate on the demand for new and remanufactured products with centralized decision making are greater. Especially, the increase in the demand for remanufactured products is more evident. (3) Under capand-trade regulations, the demand for new and remanufactured products is less than that without a constraint on carbon emissions. However, the effects on the demand for new products are greater than those on remanufactured products. This trend occurs because the carbon emissions generated by manufacturing new products are larger than those generated by remanufactured products.

Figure 3(a) shows the sales price for remanufactured products decreases as yield rate increases. However, the magnitude of the decrease with centralized decision making is more evident than that with decentralized decision making. This finding is explained by the fact that a high yield rate implies a low remanufacturing cost, which allows the TPR to lower its sales price. Under cap-and-trade regulations, the sales price is higher than that without a constraint on carbon emissions. This occurs because cap-and-trade regulations cause an increase of the TPR's remanufacturing cost. Figure 3(b) indicates that in all four cases, acquisition price first increases and then decreases as yield rate increases. This occurs because at the beginning, as yield rate increases, the demand for remanufactured products increases. However, when yield rate reaches a threshold, the demand for remanufactured products and acquisition price for used products reach the maximum since the TPR can collect enough used products at a low acquisition price to satisfy the demand for remanufactured products. As shown in Figure 3(b), with centralized decision making, the acquisition price clearly varies, but with decentralized decision making, the price almost maintains a stable level with respect to yield rate. And the aforementioned threshold of yield rate with centralized decision making is higher than that with decentralized decision making. This implies that compared to decentralized decision making, centralized decision making urges the TPR to improve yield rate and achieve more environmental benefits. As regards the constraint on 


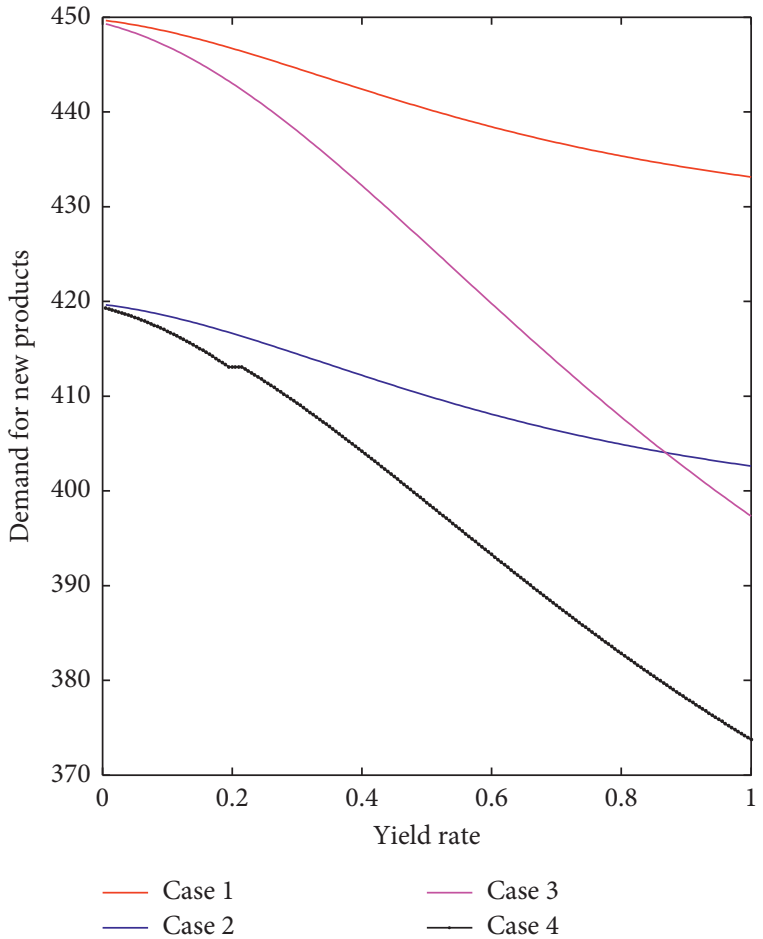

(a)

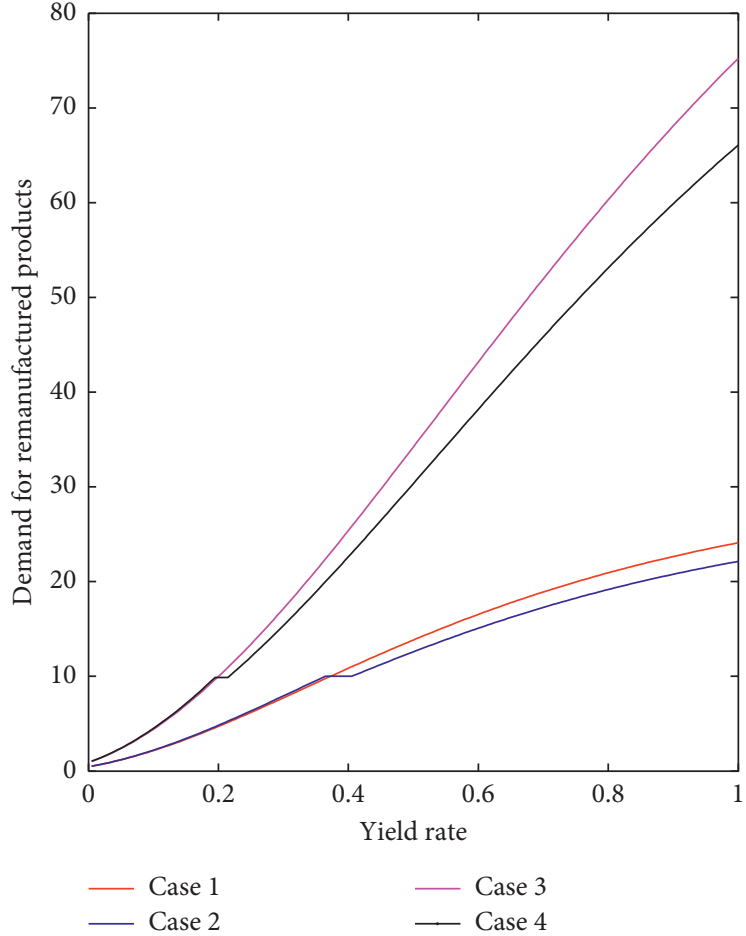

(b)

Figure 2: (a) Manufacturing quantity/demand for new products and (b) remanufacturing quantity/demand for remanufactured products vs. yield rate.

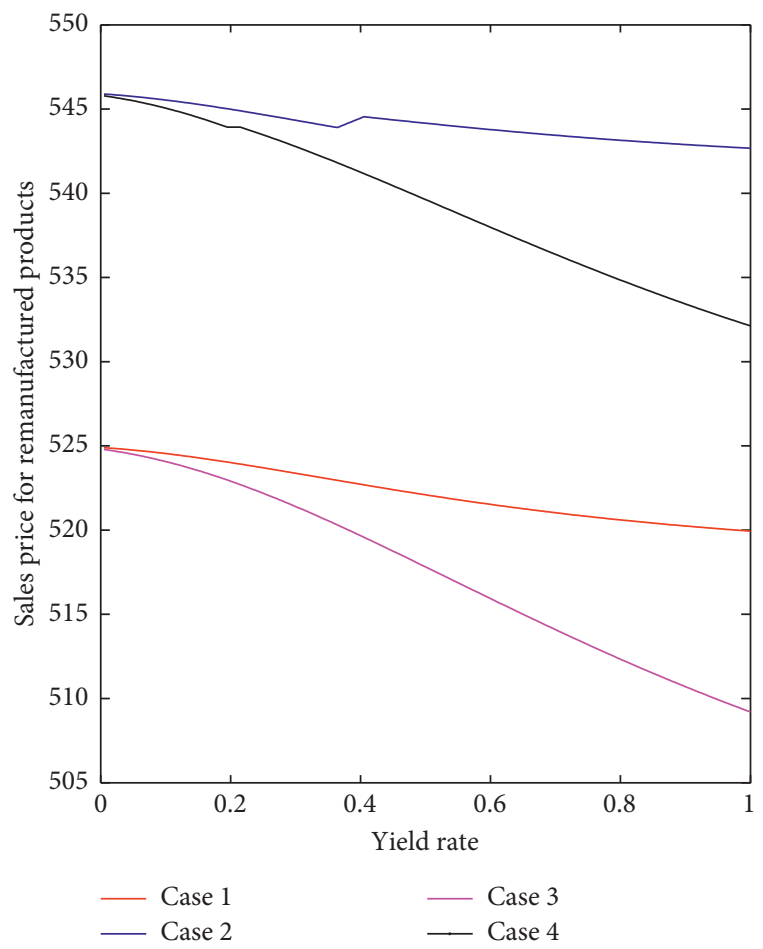

(a)

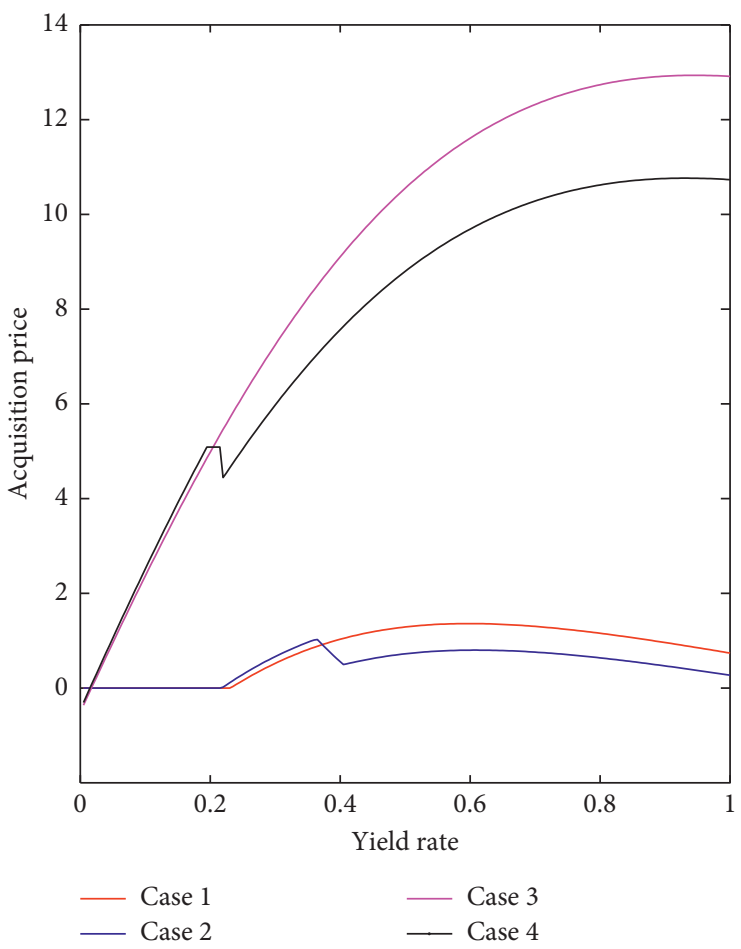

(b)

FIGURE 3: (a) Sales price for remanufactured products and (b) acquisition price for used products vs. yield rate. 


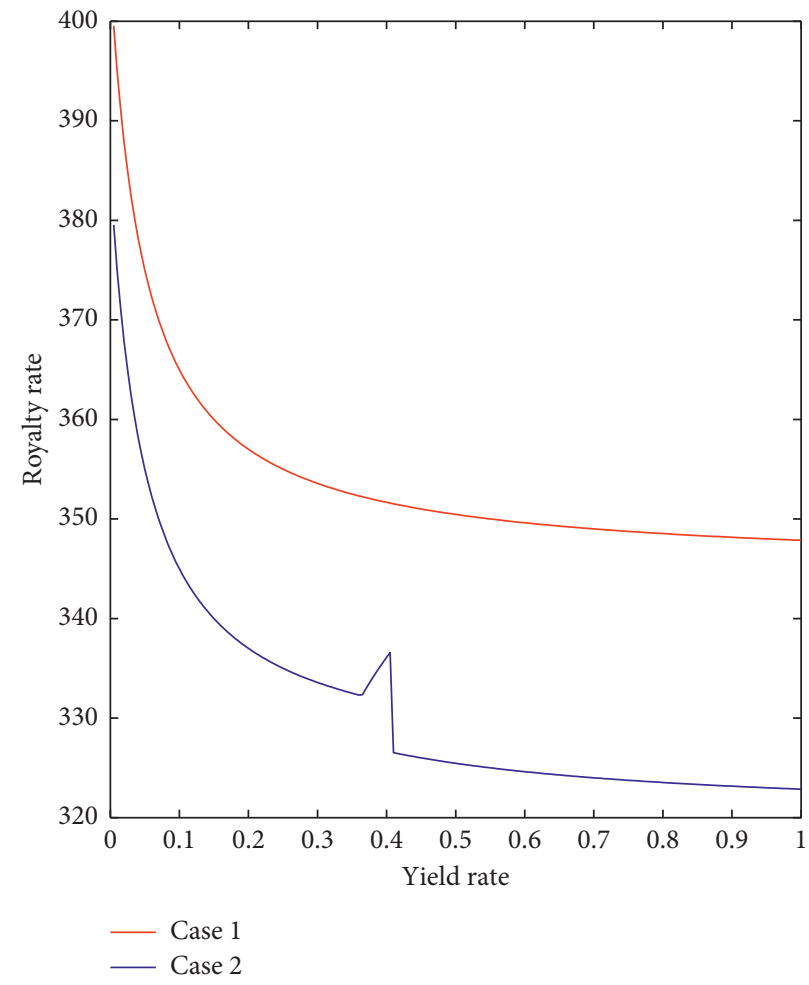

FIgURE 4: Royalty rate vs. yield rate.

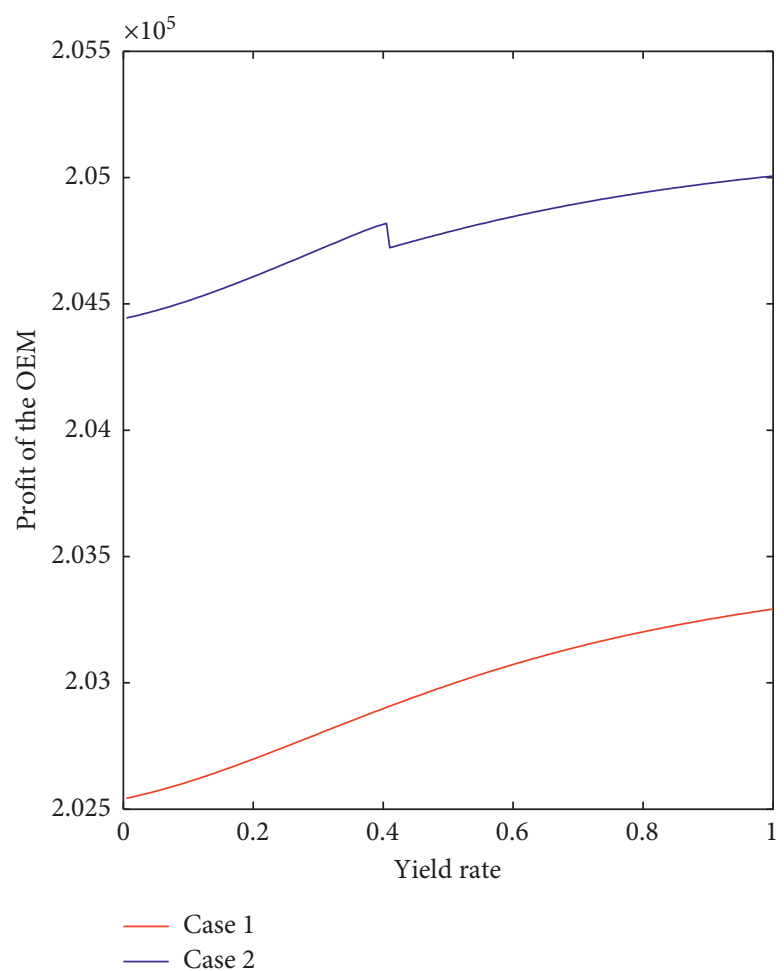

(a)

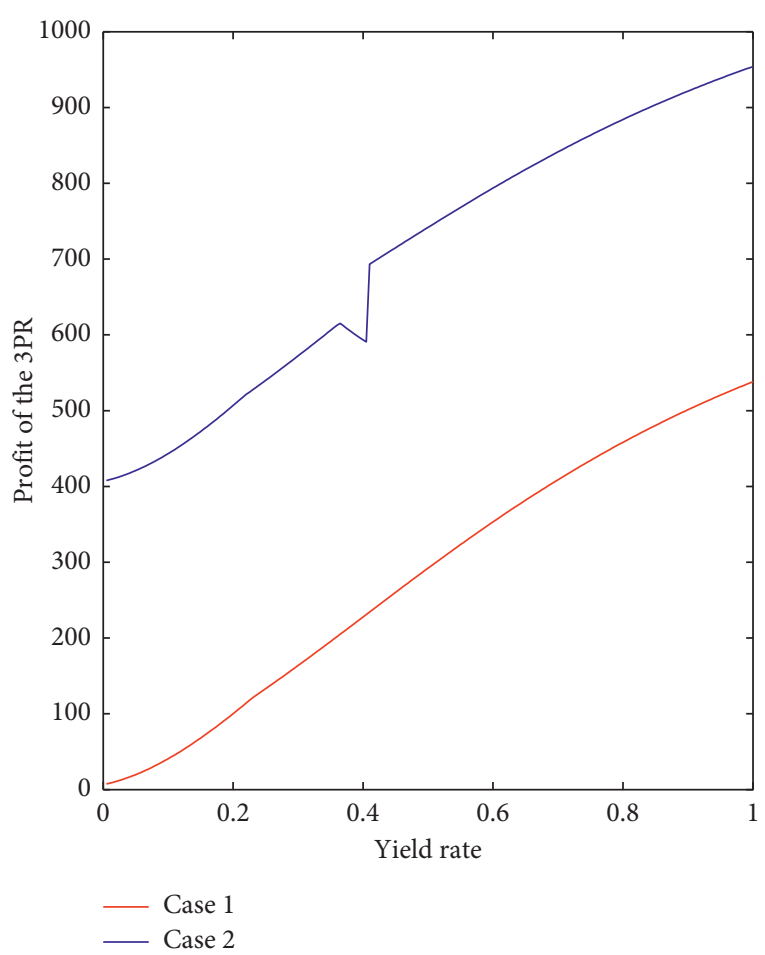

(b)

FIgure 5: Profit of (a) the OEM and (b) the TPR vs. yield rate. 


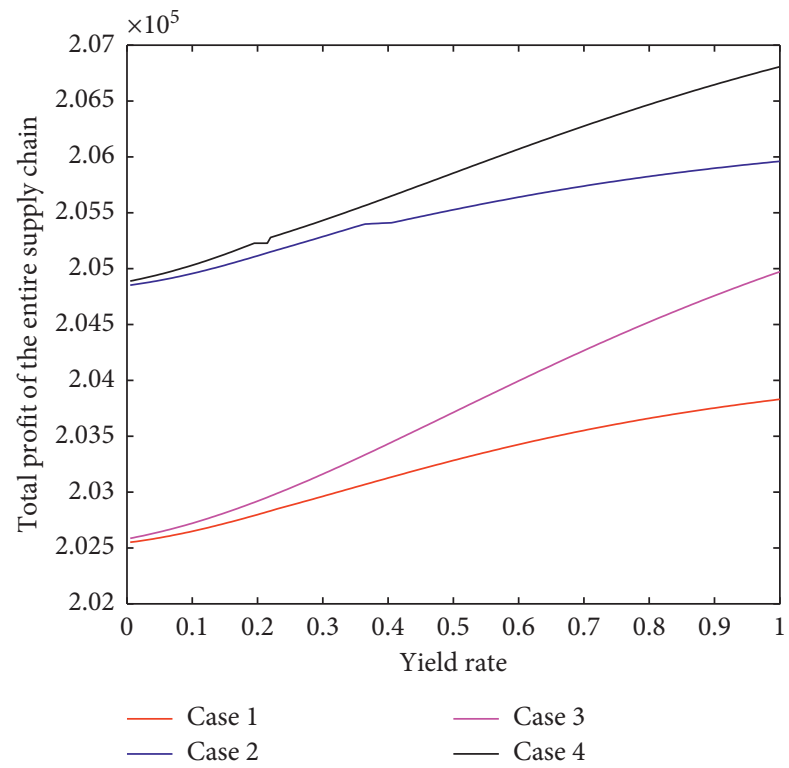

FIgURE 6: Total profit of the entire supply chain vs. yield rate.

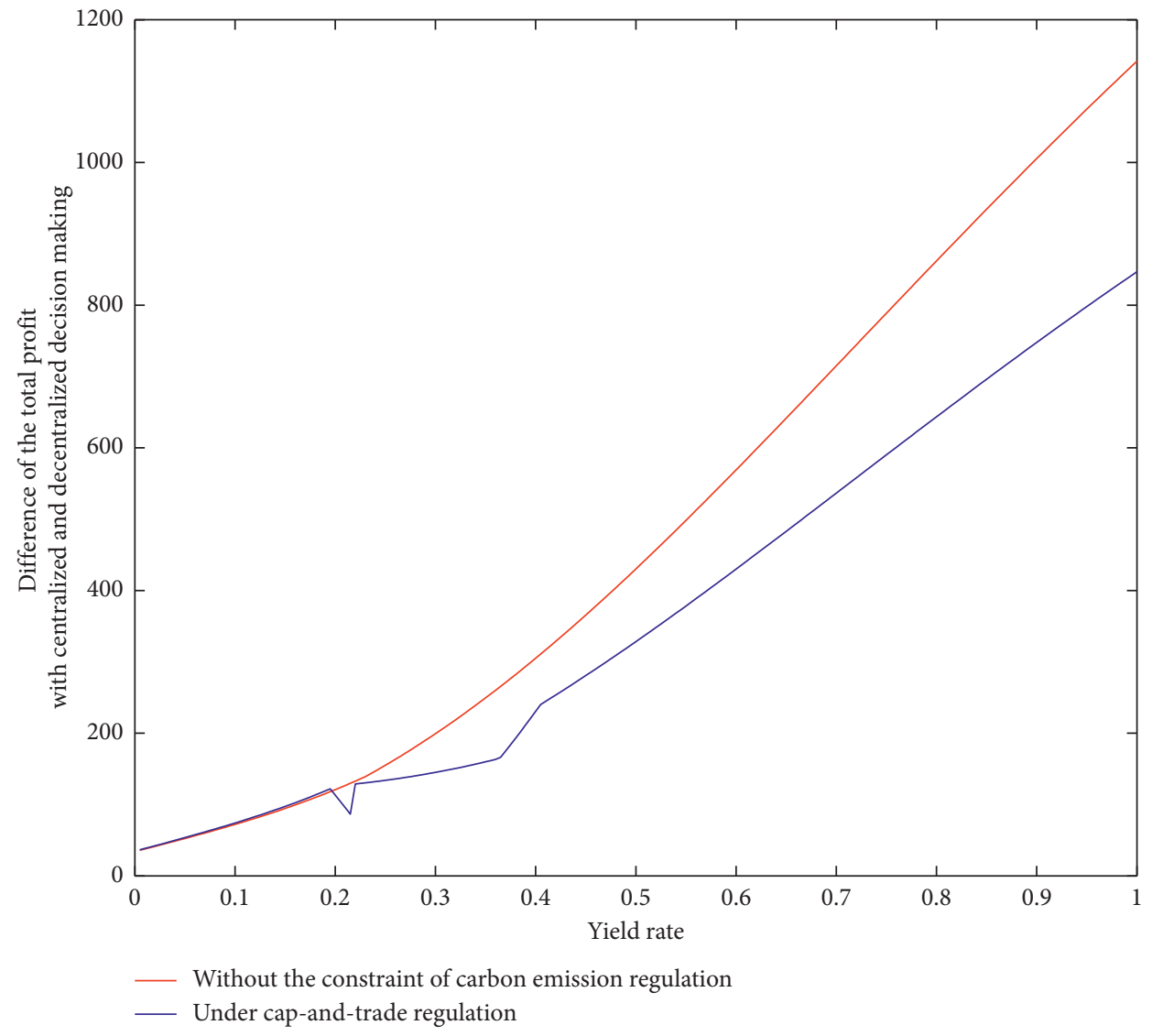

Figure 7: Difference in total profit with centralized and decentralized decision making vs. yield rate.

carbon emissions, the acquisition price under cap-and-trade regulations is relatively lower, which indicates that cap-andtrade regulations can provide a stronger incentive for TPRs to further collect used products owning to a low price.
As evident from Figure 4, regardless of a constraint on carbon emissions or not, royalty rate decreases as the yield rate increases, but decreases more when yield rate is low. Compared to the case without a constraint on carbon 


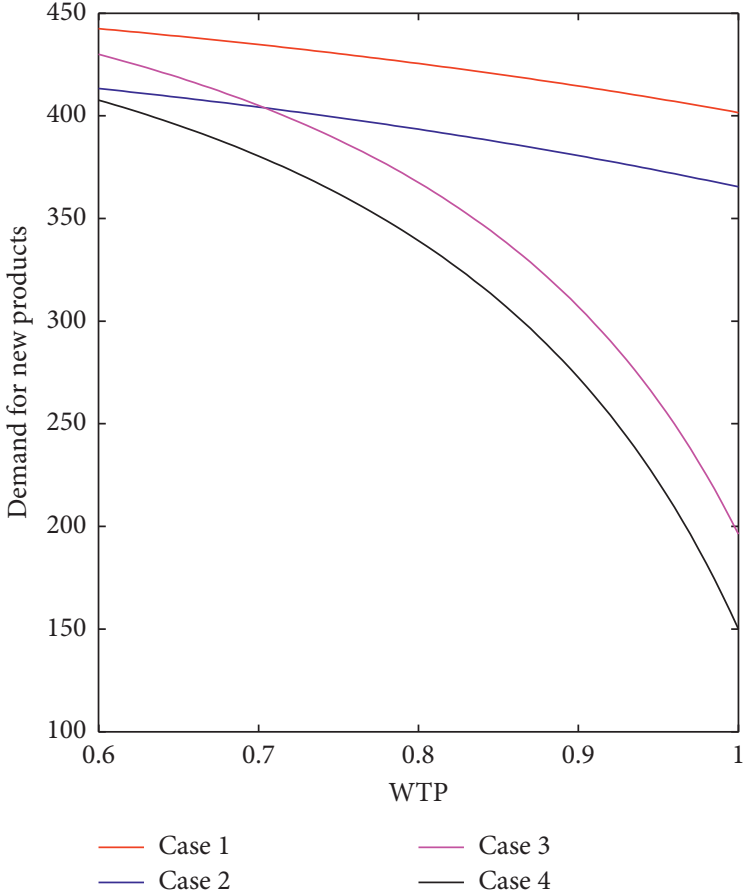

(a)

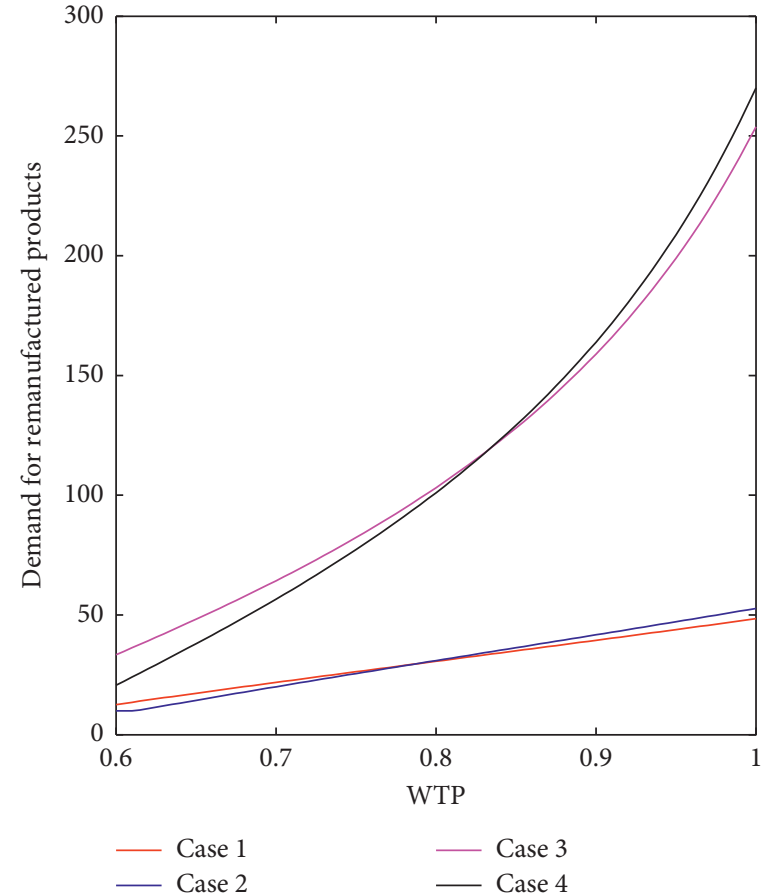

(b)

FIGURE 8: (a) Manufacturing quantity/demand for new products and (b) remanufacturing quantity/demand for remanufactured products vs. WTP.

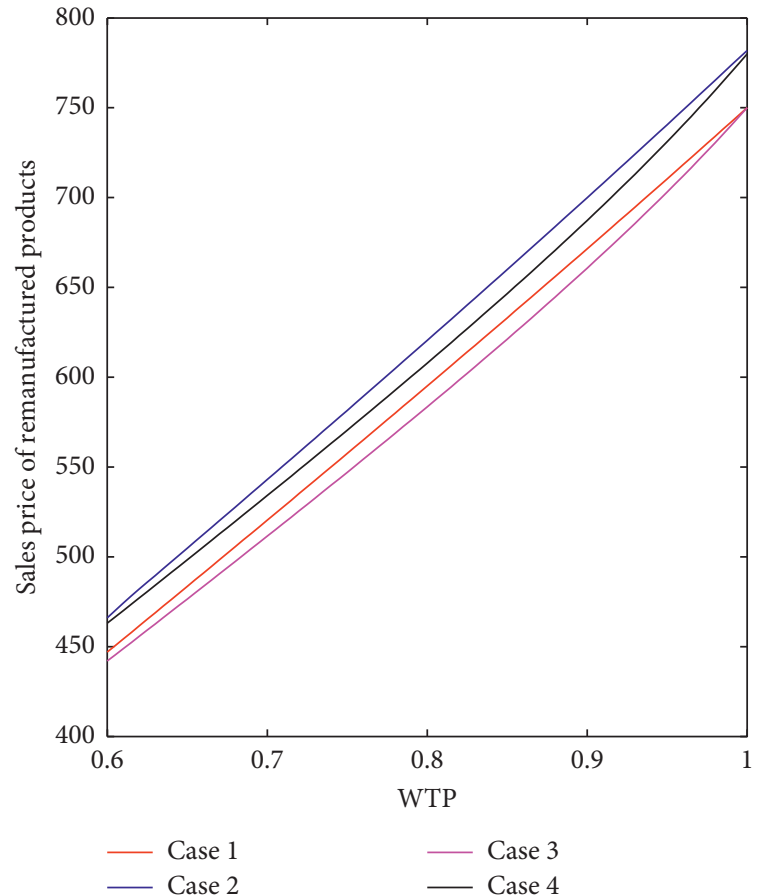

(a)

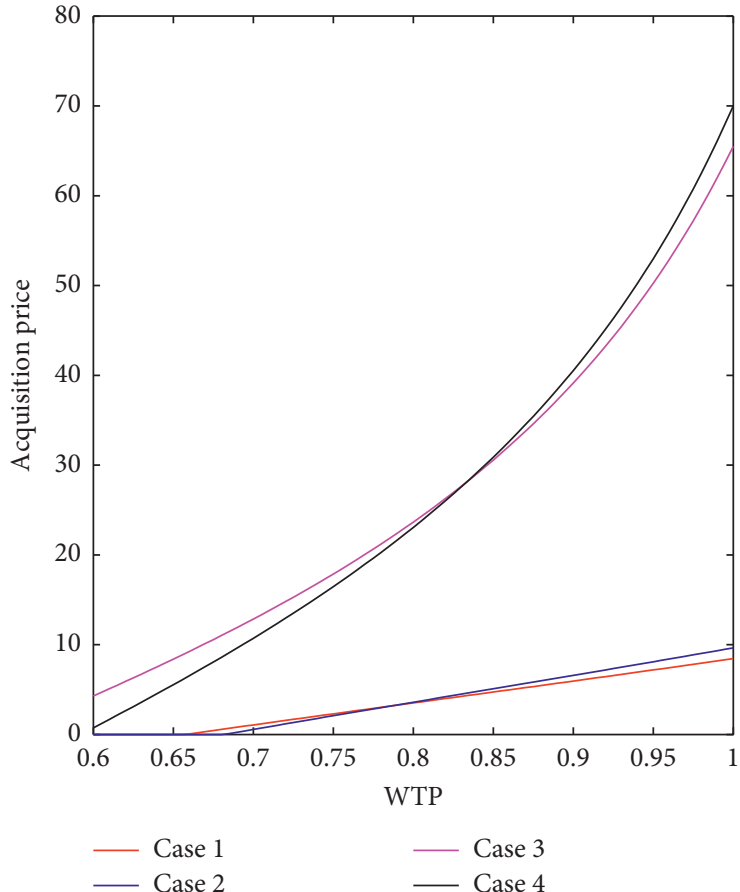

(b)

FIGURE 9: (a) Sales price for remanufactured products and (b) acquisition price for used products vs. WTP. 


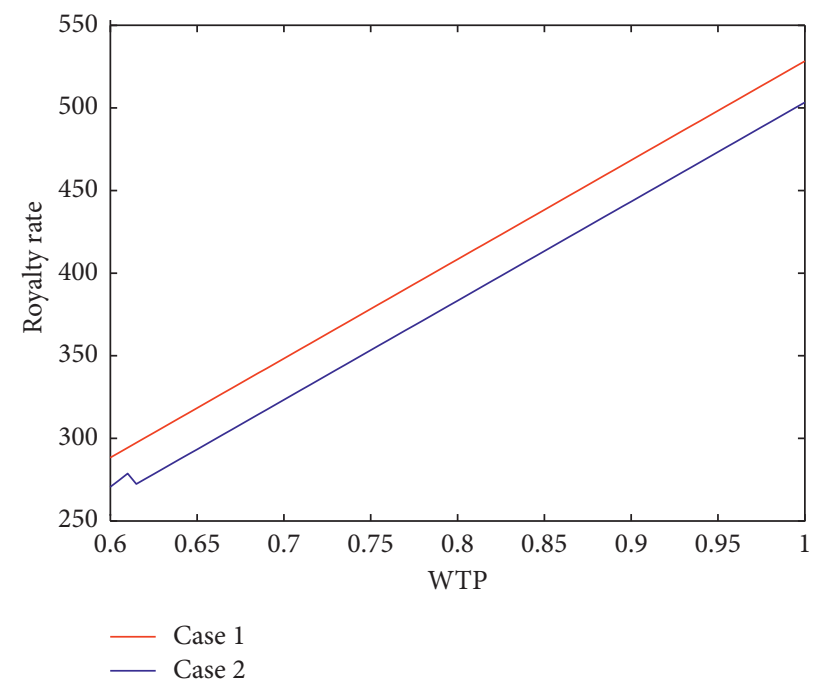

FIgURE 10: Royalty rate vs. WTP.

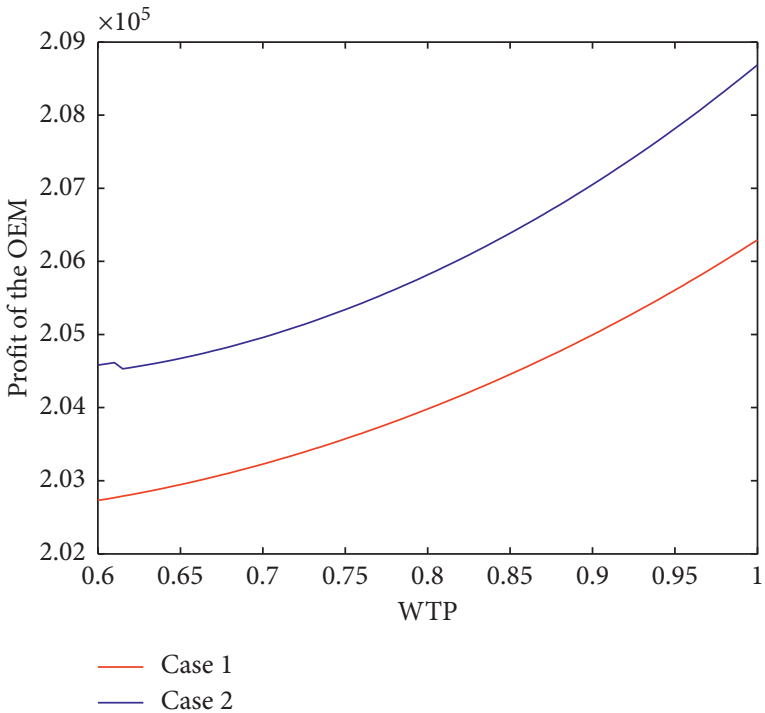

(a)

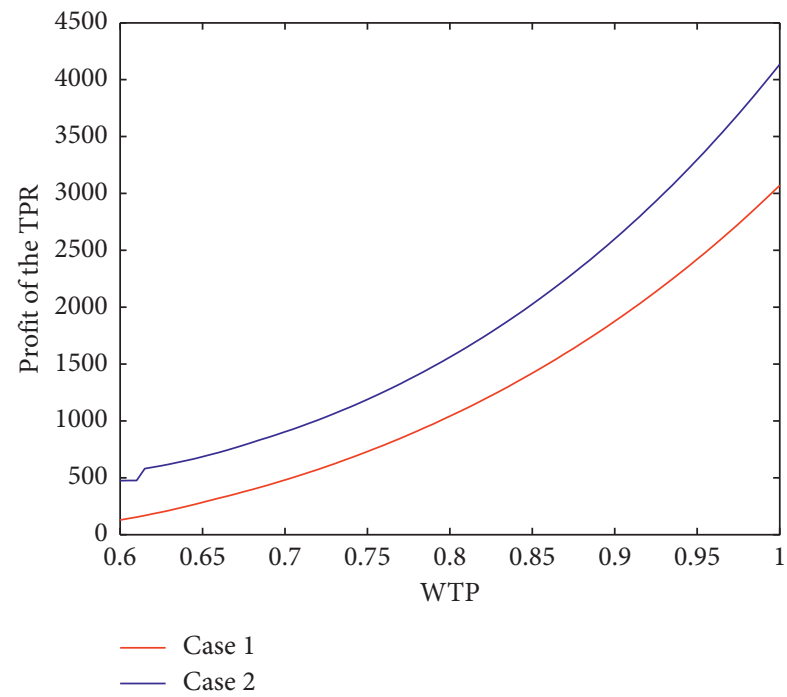

(b)

FIgure 11: Profit of (a) the OEM and (b) the TPR vs. WTP.

emissions, the royalty rate is lower under cap-and-trade regulations, which means the implementation of cap-andtrade regulations can motivate the OEM to reduce the royalty rate. As a result, the TPR benefits from remanufacturing with a low royalty fee. In addition, the increase in yield rate increases the demand for remanufactured products, for which the OEM still can maintain a high total royalty fee, thereby forming a virtuous cycle between the OEM and the TPR.

In Figure 5, the profit of the OEM and the TPR increases as yield rate increases regardless of the presence of a constraint on carbon emissions. This finding suggests that improving yield rate is a satisfactory measure to increase the profits of the OEM and the TPR. Figure 5 further illustrates that the profit under cap-and-trade regulations is higher than that without the constraint on carbon emissions. However, this result depends on the size of the carbon emissions cap that the government allocates to the TPR and the OEM. If the carbon emissions cap is not sufficiently high, then the profit under cap-and-trade regulations may be even lower than that without a constraint on carbon emissions.

Figure 6 demonstrates that the total profit of the entire supply chain increases in all four cases. Under cap-and-trade regulations, the total profit is higher than that in the case without the constraint on carbon emissions, which indicates the implementation of cap-and-trade regulations can improve the supply chain's profits. Moreover, the total profit with centralized decision making is higher than that with decentralized decision making. Figure 7 shows the difference in the total profit with centralized and decentralized decision 


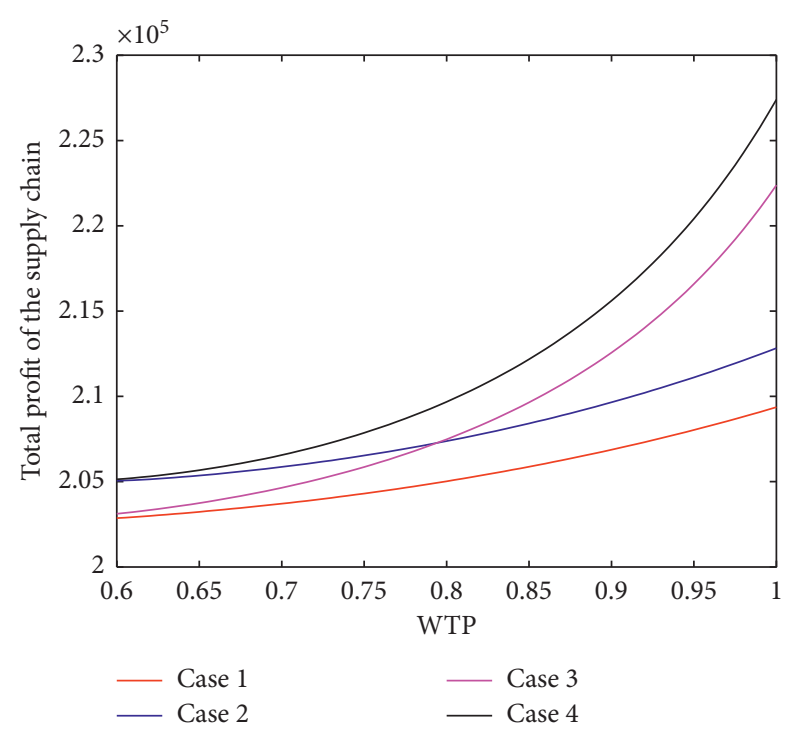

FIgURE 12: Total profit of the entire supply chain vs. WTP.

making (i.e., $\prod_{s}^{* *}-\left(\prod_{2 m}^{*}+\prod_{2 r}^{*}\right)$, which we denote as $\left.\Delta \prod_{s}\right)$ with respect to yield rate. Overall, the difference increases with respect to yield rate. Consequently, the higher the yield rate is, the larger the effects of centralized decision making on the total profit are. However, the increase under cap-andtrade regulations is less than that without a constraint on carbon emissions.

\subsection{Effects of WTP on Optimal Decision Making. Similar to} Section 5.2, we set $\gamma=0.8$ and plot a series of figures reflecting the effects as follows.

Figure 8 illustrates that regardless of cap-and-trade regulations or a lack thereof, the demand for new products decreases, whereas the demand for remanufactured products increases as WTP increases. This result matches what is found in practice. It is noteworthy that the decrease in the demand for new products and the increase in the demand for remanufactured ones with centralized decision making are more substantial than that in the case with decentralized decision making. This result signifies that the effects of decision-making approach on the demand for new and remanufactured products are more significant. In addition, under cap-and-trade regulations, the demand for new products is always lower than that in that case without a constraint on carbon emissions. Accordingly, the implementation of cap-and-trade regulations can motivate the TPR to remanufacture more used products by taking full advantage of the low carbon emissions.

Figure 9(a) indicates that as WTP increases, the sales price for remanufactured products increases rapidly in all four cases. The difference among the four cases is not highly significant. This suggests that decision-making approach and carbon emission regulations do not substantially affect remanufactured products' sales price with respect to WTP. Figure 9(b) illustrates that the acquisition price also increases with WTP in all four cases. However, the increases are more apparent with centralized than with decentralized decision making. With respect to WTP, the effect of cap-and-trade regulations on acquisition price is negligible.

Figure 10 shows that the royalty rate increases with WTP in Case 1 and Case 2. The reason is because an increase in WTP makes remanufactured products more competitive in the market, which in turn implies that the TPR will own more market share. To respond to this threat, the OEM will increase the royalty rate, which is in accord with Proposition 3.

As seen in Figure 11, with the increase of WTP, both the OEM and the TPR profits increase with or without the constraint of cap-and-trade regulations. However, under cap-and-trade regulations, the profit is always higher. This indicates the implementation of cap-and-trade regulations is helpful not only for the OEM but also for the TPR.

Figure 12 shows that as WTP increases, the total profit of the entire supply chain increases in all four cases, but increases more with centralized decision making. This result declares that centralized decision making is a more economical approach to the supply chain compared to decentralized decision making.

\section{Conclusions and Future Research}

In this paper, we study the effects of cap-and-trade regulations on the optimal decisions for an OEM and an authorized TPR in a two-echelon CLSC. In this proposed CLSC, the OEM only manufactures new products but no remanufactured products in scenario 1 , and in scenario 2 the OEM still produces new products but competes with an authorized TPR. This authorized TPR collects and remanufactures used products with the patent licensing from the OEM. In this context, we investigate the optimal operational decisions of both parties with decentralized and centralized decision making under cap-and-trade regulations in a Stackelberg model. 
The results indicate the following. (1) The implementation of carbon cap-and-trade regulations causes lower royalty rate and less manufacturing quantity, but higher sales prices for new and remanufactured products. Cap-andtrade regulations are helpful not only for the OEM but also for the TPR. (2) The optimal operational decisions of the OEM and the TPR are affected by the trading price of carbon emissions permits and their carbon emissions caps allocated by the government. Whether the TPR accepts authorization remanufacturing or not depends on the ratio of carbon emission cap to carbon emissions caused by producing remanufactured product. (3) With centralized decision making, the total profit of the entire supply chain can be improved. In this situation, the acquired quantity of the used products collected by TPRs is more considerable and the consumers can buy remanufactured products at lower prices than those with decentralized decision making. (4) As yield rate and WTP increase, total profit increases. Furthermore, the profit is highly sensitive to WTP. Therefore, to improve their benefits, TPRs can prioritize increasing customers' WTP and subsequently improving yield rate.

This study, however, has some limitations. First, other carbon emission regulations are not considered. Extending the current work and investigating how other regulations affect decisions and the differences among them presents a worthwhile concern. Second, a deterministic yield rate is assumed in this paper. More practical implications can perhaps be obtained by setting a stochastic yield rate. Finally, in this study, we considered the demand in a deterministic case; extending this study to a stochastic case presents another future research direction.

\section{Appendix}

\section{A. Proof of Proposition 1}

By substituting equation (1) into equation (5), we can obtain $\partial^{2} \prod_{1 m} / \partial^{2} q_{1 m}=-2<0$.

We set the first partial derivative of equation (5) with respect to $q_{1 m}$ equal to zero. Thus, when $M_{m} \geq q_{1 m} e_{m}$,

$$
q_{1 m}=\left(A-c_{m}-\varepsilon_{1} e_{m}\right) / 2 \text {. }
$$

Similarly, when $M_{m}<q_{1 m} e_{m}$

$$
q_{1 m}^{\prime \prime}=\left(A-c_{m}-\varepsilon_{2} e_{m}\right) / 2 \text {. }
$$

Hence, the profit function $\prod_{1 m}$ consists of two pieces of parabolas with an intersection point. We denote the intersection point as $C_{1}\left(M_{m} / e_{m}, M_{m} / e_{m}\left(A-c_{m}-M_{m} / e_{m}\right)\right)$. When $q_{1 m} \leq M_{m} / e_{m}$, the profit function is described as a piece of parabola with apex $A_{1}\left(\left(A-c_{m}-\varepsilon_{1} e_{m}\right) / 2\right.$, $\left.\left(A-c_{m}-\varepsilon_{1} e_{m}\right)^{2} / 4+\varepsilon_{1} M_{m}\right)$; when $q_{1 m} \geq M_{m} / e_{m}$, the profit function is described as a piece of parabola with apex $B_{1}\left(\left(A-c_{m}-\varepsilon_{2} e_{m}\right) / 2,\left(A-c_{m}-\varepsilon_{2} e_{m}\right)^{2} / 4+\varepsilon_{2} M_{m}\right)$. Since we assume $\varepsilon_{1}<\varepsilon_{2}$, then $q_{1 m}>q_{1 m}$, i.e., apex $A_{1}$ lies in the right of apex $B_{1}$. There are three cases depending on the relationship among $M_{m} / e_{m}, \overrightarrow{q_{1 m}}$ and $q_{1 m}$.

(i) When $M_{m} / e_{m}<q_{1 m}^{\prime \prime}$, $\left\{\begin{array}{ll}\prod_{1 m \mid q_{1 m}=M_{m} / e_{m}} & q_{1 m} \leq M_{m} / e_{m} \\ \prod_{1 m \mid q_{1 m}=\dot{q}_{1 m}} & q_{1 m}>M_{m} / e_{m}\end{array}\right.$. $\max \prod_{1 m}=$ $\prod_{1 m \mid q_{1 m}=M_{m} / e_{m}}<\prod_{1 m \mid q_{1 m}=q_{1 m}^{\prime}}$, then $q_{1 m}^{*}=q_{1 m}^{\prime}$.

Since

(ii) When $q_{1 m}^{\prime} \leq M_{m} / e_{m} \leq q_{1 m}, q_{1 m}^{*}=M_{m} / e_{m}$.

(iii) When

$$
\begin{aligned}
& \left\{\begin{array}{ll}
\prod_{1 m \mid q_{1 m}=q_{1 m}} & q_{1 m} \leq M_{m} / e_{m} \\
\prod_{1 m \mid q_{1 m}=M_{m} / e_{m}} & q_{1 m}>M_{m} / e_{m}
\end{array} .\right. \\
& \prod_{1 m \mid q_{1 m}=M_{m} / e_{m}}<\prod_{1 m \mid q_{1 m}=q_{1 m}} \text {, then } q_{1 m}^{*}=q_{1 m} .
\end{aligned}
$$

$\max \prod_{1 m}=$ Since

The optimal decisions are summarized as follows:

$$
q_{1 m}^{*}= \begin{cases}q_{1 m}^{\prime}, & M_{m} / e_{m}<q_{1 m}^{\prime}, \\ M_{m} / e_{m}, & \dot{q}_{1 m}^{\prime} \leq M_{m} / e_{m} \leq q_{1 m}^{\prime}, \\ q_{1 m}^{\prime}, & M_{m} / e_{m}>q_{1 m}^{\prime},\end{cases}
$$

Let $B=\left\{\begin{array}{l}\varepsilon_{1} e_{m}, M_{m} / e_{m}>q_{2 m}^{\prime}, \\ \varepsilon_{2} e_{m}, M_{m} / e_{m}<q_{2 m},\end{array}\right.$. Therefore, we obtain

We then substitute equation (9) into equations (1) and (5) and obtain equations (10) and (12).

\section{B. Proof of Proposition 2}

By substituting equations (2) and (4) into equation 8 , we can obtain $\partial^{2} \prod_{2 r} / \partial^{2} q_{2 r}=-2 \theta-2 / \beta \gamma^{2}<0$ and

$$
\begin{aligned}
& \frac{\partial \prod_{2 r}}{\partial q_{2 r}}=\left\{\begin{array}{rr}
\frac{-2\left(\theta \beta \gamma^{2}+1\right)}{\beta \gamma^{2}} q_{2 r}+\left[\theta\left(A-q_{2 m}^{*}\right)-c_{r}-\varepsilon_{1} e_{r}-f^{*}\right]+\frac{\beta \gamma g+\alpha \gamma}{\beta \gamma^{2}}, & \text { when } M_{r} \geq q_{2 r} e_{r}, \\
\frac{-2\left(\theta \beta \gamma^{2}+1\right)}{\beta \gamma^{2}} q_{2 r}+\left[\theta\left(A-q_{2 m}^{*}\right)-c_{r}-\varepsilon_{2} e_{r}-f^{*}\right]+\frac{\beta \gamma g+\alpha \gamma}{\beta \gamma^{2}}, & \text { when } M_{r}<q_{2 r} e_{r} .
\end{array}\right. \\
& q_{2 r}=\left\{\beta \gamma^{2}\left[\theta\left(A-q_{2 m}^{*}\right)-\varepsilon_{1} e_{r}-c_{r}-f^{*}\right]\right.
\end{aligned}
$$

When $M_{r} \geq q_{2 r} e_{r}$, we let $q_{2 r}$ as the value of $q_{2 r}$ when the first partial derivative of equation (8) with respect to $q_{2 r}$ equals to zero. We thus obtain 
Similarly, when $M_{r}<q_{2 r} e_{r}$, we let $\stackrel{\prime}{2 r}_{2 r}$ as the value of $q_{2 r}$ when the first partial derivative of equation (8) with respect to $q_{2 r}$ equals to zero. We can obtain

$$
\begin{aligned}
q_{2 r}^{\prime \prime}= & \left\{\beta \gamma^{2}\left[\theta\left(A-q_{2 m}^{*}\right)-\varepsilon_{2} e_{r}-c_{r}-f^{*}\right]+\beta \gamma g+\alpha \gamma\right\} / \\
& \cdot\left(2 \theta \beta \gamma^{2}+2\right),
\end{aligned}
$$

Same as Proposition 2, the profit function $\prod_{2 r}$ consists of two pieces of parabolas with an intersection point $C_{2}\left(M_{r} / e_{r}, M_{r} / e_{r}\left\{\left[\theta\left(A-q_{2 m}^{*}\right)-\mathrm{c}_{\mathrm{r}}-\mathrm{f}^{*}+(\mathrm{g} \beta \gamma+\alpha \gamma) / \beta \gamma^{2}\right]\right.\right.$ $\left.\left.-\left(\theta \beta \gamma^{2}+1\right) / \beta \gamma^{2} \cdot\left(M_{m} / e_{m}\right)\right\}\right)$. When $q_{2 r} \leq M_{r} / e_{r}$, the profit function is described as a piece of parabola with apex $A_{2}\left(q_{2 r}^{\prime}, \prod_{2 r \mid q_{2 r}=q_{2 r}^{\prime}}\right.$; when $q_{2 r}>M_{r} / e_{r}$, the profit function is described as a piece of parabola with apex $B_{2}\left(q_{2 r}^{\prime}, \prod_{2 r \mid q_{2 r}=q_{2 r}^{\prime}}\right)$. Since we assume $\varepsilon_{1}<\varepsilon_{2}$, then $q_{2 r}^{\prime}>q_{2 r}^{\prime}$, i.e., apex $A_{2}$ lies in the right of apex $B_{2}$. There are three cases depending on the relationship among $M_{r} / e_{r}, q_{2 r}^{\prime}$ and $q_{2 r}^{\prime}$.
(i) When $\quad M_{r} / e_{r}<q_{2 r}^{\prime}, \quad \max \prod_{2 r}=$ $\left\{\begin{array}{lll}\prod_{2 r \mid q_{2 r}=M_{r} / e_{r}} & q_{2 r} \leq M_{r} / e_{r} . & \text { Since } \\ \prod_{2 r \mid q_{2 r}=q_{2 r}} & q_{2 r}>M_{r} / e_{r} . & \end{array}\right.$

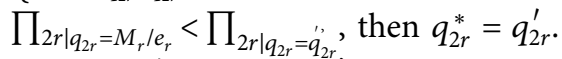

(ii) When $q_{2 r}^{\prime} \leq M_{r} / e_{r} \leq q_{2 r}, \quad q_{2 r}^{*}=M_{r} / e_{r}$. But if $q_{2 r}^{*}=M_{r} / e_{r}, \prod_{2 m}$ increases monotonously vs. royalty rate $f$, for which the best choice for the TPR is to refuse being authorized for remanufacturing, i.e., $q_{2 r}^{*}=0$.

(iii) When

$$
\begin{aligned}
& \max \prod_{2 r}= \begin{cases}\prod_{2 r \mid q_{2 r}=q_{2 r}} & q_{2 r} \leq M_{r} / e_{r} \\
\prod_{2 r \mid q_{2 r}=M_{r} / e_{r}} & q_{2 r}>M_{r} / e_{r}\end{cases} \\
& \text { Since } \prod_{2 r \mid q_{2 r}=M_{r} / e_{r}}<\prod_{2 r \mid q_{2 r}=q_{2 r}^{\prime}}, \text { then } q_{2 r}^{*}=q_{2 r} .
\end{aligned}
$$

The optimal decisions are summarized as follows:

$$
q_{2 r}^{*}=\left\{\begin{array}{l}
q_{2 r}^{\prime}, \quad M_{r} / e_{r}<q_{2 r}^{\prime}, \\
0, \quad q_{2 r}^{\prime} \leq M_{r} / e_{r} \leq q_{2 r}^{\prime}, \\
q_{2 r}, \quad M_{r} / e_{r}>q_{2 r}^{\prime},
\end{array}\right.
$$

Let $C=\left\{\begin{array}{ll}\varepsilon_{1} e_{r}, & M_{r} / e_{r}>q_{2 r}, \\ \varepsilon_{2} e_{r}, & q_{2 r}^{\prime}>M_{r} / e_{r},\end{array}\right.$. Therefore, we obtain

We then substitute equation (13) into equations (3)-(5) and obtain equations (14)-(17).

\section{Proof of Proposition 3}

By substituting equation (3) to equation (7), we can obtain the following:

(1) When $q_{2 r}^{\prime} \leq M_{r} / e_{r} \leq q_{2 r}^{\prime}$,

$$
\begin{aligned}
\prod_{2 m}= & -q_{2 m}^{2}+\left(A-c_{m}-\frac{\theta M_{r}}{e_{r}}\right) q_{2 m}+\frac{M_{r} f}{e_{r}}+\varepsilon_{1}\left(M_{m}-q_{2 m} e_{m}\right)^{+} \\
& -\varepsilon_{2}\left(q_{2 m} e_{m}-M_{m}\right)^{+}
\end{aligned}
$$

By observing equation (A 6), for the OEM, when $f$ tends to infinity, the profit tends to maximization. It is impossible for the TPR to accept authorization remanufacturing with so high royalty rate. Therefore, in this case, the TPR will choose to remanufacture zero products, i.e., $q_{2 r}^{*}=0$. Then,

$$
\begin{aligned}
\prod_{2 m}= & q_{2 m}\left(A-\mathrm{q}_{2 \mathrm{~m}}-\mathrm{c}_{\mathrm{m}}\right)+\varepsilon_{1}\left(M_{m}-q_{2 m} e_{m}\right)^{+} \\
& -\varepsilon_{2}\left(q_{2 m} e_{m}-M_{m}\right)^{+}
\end{aligned}
$$

We can obtain $\partial^{2} \prod_{2 r} / \partial^{2} q_{2 r}=-2<0$. The optimal decisions of the OEM are as the same as in scenario 1 .

(2) When $M_{r} / e_{r}<q_{2 r}^{\prime}$ or $M_{r} / e_{r}>q_{2 r}^{\prime}$,

$$
\begin{aligned}
& \frac{\partial^{2} \prod_{2 m}}{\partial^{2} q_{2 m}}=-2+\frac{\theta^{2} \beta \gamma^{2}}{\theta \beta \gamma^{2}+1}<-2+\frac{\theta^{2} \beta \gamma^{2}}{\theta^{2} \beta \gamma^{2}+1}<0, \\
& \frac{\partial^{2} \prod_{2 m}}{\partial^{2} f}=-\frac{\beta \gamma^{2}}{\theta \beta \gamma^{2}+1}<0,
\end{aligned}
$$

then the Hessian matrix of equation (8) is

$$
H=\left[\begin{array}{cc}
-2+\frac{\theta^{2} \beta \gamma^{2}}{\theta \beta \gamma^{2}+1} & 0 \\
0 & -\frac{\beta \gamma^{2}}{\theta \beta \gamma^{2}+1}
\end{array}\right] .
$$

It is apparent that $|H|>0$. Therefore, the Hessian matrix is negative definite and the profit function is concave.

When $M_{m} \geq q_{2 m} e_{m}$, we let $q_{2 m}^{\prime}$ and $f^{\prime}$ as the value of $q_{2 m}$ and $f$ when the first partial derivative of equation (8) with respect to $q_{2 m}$ and $f$ equals to zero, respectively. We then obtain 


$$
\begin{aligned}
q_{2 m}^{\prime} & =\frac{2\left(A-c_{m}\right)\left(\theta \beta \gamma^{2}+1\right)+\theta \gamma\left[\beta \gamma\left(c_{r}-\theta A\right)-\beta g-\alpha+C\right]-2\left(\theta \beta \gamma^{2}+1\right) \varepsilon_{1} e_{m}}{4 \theta \beta \gamma^{2}-2 \theta^{2} \beta \gamma^{2}+4}, \\
f^{\prime} & =\left[\beta \gamma\left(\theta A-c_{r}-C\right)+\beta g+\alpha\right] / 2 \beta \gamma .
\end{aligned}
$$

Similarly, when $M_{m}<q_{2 m} e_{m}$, we let $q_{2 m}^{\prime}$ and $f^{\prime}$ as the value of $q_{2 m}$ and $f$ when the first partial derivative of equation
(8) with respect to $q_{2 m}$ and $f$ equals to zero, respectively. We thus obtain

$$
\begin{aligned}
& q_{2 m}^{\prime}=\frac{2\left(A-c_{m}\right)\left(\theta \beta \gamma^{2}+1\right)+\theta \gamma\left[\beta \gamma\left(c_{r}-\theta A\right)-\beta g-\alpha+C\right]-2\left(\theta \beta \gamma^{2}+1\right) \varepsilon_{2} e_{m}}{4 \theta \beta \gamma^{2}-2 \theta^{2} \beta \gamma^{2}+4}, \\
& f^{\prime}=f^{\prime}=\left[\beta \gamma\left(\theta A-c_{r}-C\right)+\beta g+\alpha\right] / 2 \beta \gamma
\end{aligned}
$$

The profit function $\prod_{2 m}$ consists of two pieces of curved surfaces with an intersection line $q_{2 m}=M_{m} / e_{m}$. When $q_{2 m}=M_{m} / e_{m}, \prod_{2 m}$ can be described as

$$
\prod_{2 m}=\frac{M_{m}}{e_{m}}\left(A-c_{m}-\frac{M_{m}}{e_{m}}-\theta q_{2 r}\right)+q_{2 r} f
$$

By substituting $q_{2 r}=\gamma\left\{\beta \gamma\left[\theta\left(A-q_{2 m}\right)-c_{r}-f-C\right]+\right.$ $\beta g+\alpha\} / 2 \theta \beta \gamma^{2}+2$ into equation (A.11), we can obtain

$$
\begin{aligned}
\prod_{2 m \mid q_{2 m}=M_{m} / e_{m}}= & \frac{M_{m}}{e_{m}}\left(A-c_{m}-\frac{M_{m}}{e_{m}}-\frac{\theta \gamma\left\{\beta \gamma\left[\theta\left(A-M_{m} / e_{m}\right)-c_{r}-f-C\right]+\beta g+\alpha\right\}}{2 \theta \beta \gamma^{2}+2}\right) \\
& +\frac{\gamma\left\{\beta \gamma\left[\theta\left(A-M_{m} / e_{m}\right)-c_{r}-f-C\right]+\beta g+\alpha\right\}}{2 \theta \beta \gamma^{2}+2} f .
\end{aligned}
$$

Since $\partial^{2} \prod_{2 m} / \partial^{2} f=-\beta \gamma^{2} / \theta \beta \gamma^{2}+1<0$, then we can obtain the optimal $f$ by setting the first partial derivative of equation (A.16) with respect to $f$ equal to zero, i.e., $f^{*}=f^{\prime}$.

When $q_{2 m} \leq M_{m} / e_{m}$, the profit function is described as a piece of curved surface with apex $A_{3}\left(q_{2 m}^{\prime}, f^{\prime}\right.$, $\left.\prod_{2 m \mid\left(q_{2 m}=q_{2 m}^{\prime}, f=f^{\prime}\right)}\right)$; when $q_{2 m}>M_{m} / e_{m}$, the profit function is described as a piece of curved surface with apex $B_{3}\left(q_{2 m}^{\prime}, f^{\prime}, \prod_{2 m \mid\left(q_{2 m}=q_{2 m}^{\prime}, f=f^{\prime}\right)}\right)$. Since we assume $\varepsilon_{1}<\varepsilon_{2}$, then $q_{2 m}^{\prime}>q_{2 m}^{\prime}$, i.e., apex $A_{3}$ lies in the right of apex $B_{3}$. There are three cases depending on the relationship among $M_{m} / e_{m}, q_{2 m}^{\prime}$ and $q_{2 m}^{\prime}$.

(i) When $\quad M_{m} / e_{m}<q_{2 m}^{\prime}, \quad \max \prod_{2 m}=$

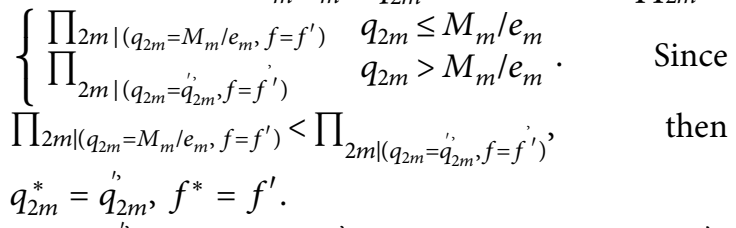

(ii) When $\stackrel{q}{2 m}^{\prime} \leq M_{m} / e_{m} \leq q_{2 m}^{\prime}, q_{2 m}^{*}=M_{m} / e_{m}, f^{*}=f^{\prime}$.

(iii) When $\max \prod_{2 m}=\left\{\begin{array}{ll}\prod_{2 m \mid}\left(q_{2 m}=q_{2 m}^{\prime}, f=f^{\prime}\right) & q_{2 m} \leq M_{m} / e_{m} \\ \prod_{2 m \mid\left(q_{2 m}=M_{m} / e_{m}, f=f^{\prime}\right)} & q_{2 m}>M_{m} / e_{m}\end{array}\right.$.
Since $\prod_{2 m \mid\left(q_{2 m}=M_{m} / e_{m}, f=f_{\prime}\right)}<\prod_{2 m \mid\left(q_{2 m}=q_{2 m}^{\prime}, f=f_{\prime}\right)}$, then $q_{2 m}^{*}=q_{2 m}^{\prime}, f^{*}=f^{\prime}$.

The optimal decisions are summarized as follows.

When $q_{2 r}^{\prime} \leq M_{r} / e_{r} \leq q_{2 r}^{\prime}, q_{2 m}^{*}=q_{1 m}^{*}$; when $M_{r} / e_{r}<q_{2 r}$ or $M_{r} / e_{r}>q_{2 r}$,

$$
\begin{aligned}
& q_{2 m}^{*}=\left\{\begin{array}{l}
q_{2 m}^{\prime}, \quad M_{m} / e_{m}<q_{2 m}^{\prime}, \\
M_{m} / e_{m}, \quad q_{2 m}^{\prime} \leq M_{m} / e_{m} \leq q_{2 m}^{\prime}, \\
q_{2 m}^{\prime}, \quad M_{m} / e_{m}>q_{2 m},
\end{array}\right. \\
& f^{*}=f ı .
\end{aligned}
$$

Let $D=\left\{\begin{array}{ll}\varepsilon_{1} e_{m}, & M_{m} / e_{m}>q_{2 m}^{\prime}, \\ \varepsilon_{2} e_{m}, & M_{m} / e_{m}<q_{2 m}^{\prime},\end{array}\right.$, and we obtain equations (20) and (21).

By substituting equations (20) and (21) into equations (2) and (6), we obtain equations (22) and (23).

\section{Proof of Proposition 4}

By substituting equation (3) to equation (26), we can obtain $\partial^{2} \prod_{s} / \partial^{2} q_{2 m}=-2, \partial^{2} \prod_{s} / \partial q_{2 m} \partial q_{2 r}=-2 \theta, \partial^{2} \prod_{s} / \partial q_{2 r} \partial q_{2 m}=$ $-2 \theta$, and $\partial^{2} \prod_{s} / \partial^{2} q_{2 r}=-2\left(\theta+\left(1 / \beta \gamma^{2}\right)\right)$; then, the Hessian matrix of equation (26) is 


$$
H=\left[\begin{array}{cc}
-2 & -2 \theta \\
-2 \theta & -2\left(\theta+\frac{1}{\beta \gamma^{2}}\right)
\end{array}\right]
$$

It is apparent that $|H|=4\left(\theta-\theta^{2}+1 / \beta \gamma^{2}\right)>0$. Therefore, the Hessian matrix is negative definite and the profit function is concave.

When $M_{m}+M_{r} \geq q_{2 m} e_{m}+q_{2 r} e_{r}$, the first partial derivatives of equation (26) with respect to $q_{2 m}$ and $q_{2 r}$ are as follows:

$$
\left\{\begin{array}{l}
\frac{\partial \prod_{s}}{\partial q_{2 m}}=-2 q_{2 m}+A-c_{m}-2 \theta q_{2 r}-\varepsilon_{1} e_{m} \\
\frac{\partial \prod_{s}}{\partial q_{2 r}}=-2 \theta q_{2 m}-2\left(\theta+\frac{1}{\beta \gamma^{2}}\right) q_{2 r}+\theta A-c_{r}+\frac{\beta g+\alpha}{\beta \gamma}-\varepsilon_{1} e_{r} .
\end{array}\right.
$$

We let $q_{2 m}^{c}$ and $q_{2 r}^{c}$ as the value of $q_{2 m}$ and $q_{2 r}$ when the first partial derivative of equation (26) with respect to $q_{2 m}$ and $q_{2 r}$ equals to zero, respectively. Thus,

$$
\left\{\begin{array}{l}
q_{2 m}^{c^{c}}=\frac{A-c_{m}-\varepsilon_{1} e_{m}}{2}-\theta q_{2 r}^{c}, \\
q_{2 r}^{c^{c}}=\frac{\gamma(\beta g+\alpha)+\beta \gamma^{2}\left[\theta c_{m}-c_{r}+\varepsilon_{1}\left(\theta e_{m}-e_{r}\right)\right]}{2\left(\theta \beta \gamma^{2}-\theta^{2} \beta \gamma^{2}-1\right)} .
\end{array}\right.
$$

Similarly, when $M_{m}+M_{r}<q_{2 m} e_{m}+q_{2 r} e_{r}$, we let $q_{2 m}^{c^{\prime \prime}}$ and $q_{2 r}^{c^{\prime \prime}}$ as the value of $q_{2 m}$ and $q_{2 r}$ when the first partial derivative of equation (26) with respect to $q_{2 m}$ and $f$ equals to zero, respectively. We thus obtain

$$
\left\{\begin{array}{l}
q_{2 m}^{c^{\prime \prime}}=\frac{A-c_{m}-\varepsilon_{2} e_{m}}{2}-\theta q_{2 r}^{c^{\prime \prime}}, \\
q_{2 r}^{c^{\prime \prime}}=\frac{\gamma(\beta g+\alpha)+\beta \gamma^{2}\left[\theta c_{m}-c_{r}+\varepsilon_{2}\left(\theta e_{m}-e_{r}\right)\right]}{2\left(\theta \beta \gamma^{2}-\theta^{2} \beta \gamma^{2}-1\right)} .
\end{array}\right.
$$

The profit function $\prod_{s}$ consists of two pieces of curved surfaces with an intersecting line $q_{2 m} e_{m}+q_{2 r} e_{r}=M_{m}+M_{r}$ where $\prod_{s}$ can be described as

$$
\begin{aligned}
\prod_{s}= & -q_{2 m}^{2}+\left(A-c_{m}\right) q_{2 m}-2 \theta q_{2 m} q_{2 r}-\left(\theta+\frac{1}{\beta \gamma^{2}}\right) q_{2 r}^{2} \\
& +\left(\theta A-c_{r}+\frac{\beta g+\alpha}{\beta \gamma}\right) q_{2 r} .
\end{aligned}
$$

By substituting $q_{2 m} e_{m}+q_{2 r} e_{r}=M_{m}+M_{r}$ into equation (A.21), we then obtain

$$
\frac{\partial^{2} \prod_{s}}{\partial^{2} q_{2 r}}=2\left[\frac{2 \theta e_{r}}{e_{m}}-\frac{e_{r}^{2}}{e_{m}^{2}}-\left(\theta+\frac{1}{\beta \gamma^{2}}\right)\right]=\frac{2\left[-\beta \gamma^{2}\left(\theta e_{m}^{2}-2 \theta e_{r} e_{m}+e_{r}^{2}\right)-e_{m}^{2}\right]}{e_{m}^{2} \beta \gamma^{2}}<\frac{-2\left[\beta \gamma^{2}\left(\theta e_{m}-e_{r}\right)^{2}+e_{m}^{2}\right]}{e_{m}^{2} \beta \gamma^{2}}<0
$$

Thus, the optimal $q_{2 r}$ (here we denote it as $q_{2 r}^{\prime \prime}$ ) to maximize the profit within the interaction line can be obtained by setting the first partial derivative of equation (A.21) with respect to $q_{2 r}$ equal to zero. We also denote the corresponding value of $q_{2 m}$ as $q_{2 m}^{\prime c}$. We note this point $\left(q_{2 m}^{\prime c}, q_{2 r}^{\prime \prime}, \prod_{s \mid\left(q_{2 m}=q_{2 m}^{\prime c}, q_{2 r}=q_{2 r}^{c}\right)}\right)$ as $C_{4}$. Then, we have

$$
\left\{\begin{array}{l}
q_{2 m}^{c^{\prime \prime}}=\frac{M_{m}+M_{r}-e_{r} q_{2 r}^{c^{\prime \prime}}}{e_{m}}, \\
q_{2 r}^{c^{\prime \prime}}=\frac{\beta \gamma^{2}\left[2\left(M_{m}+M_{r}\right)\left(e_{r}-\theta e_{m}\right)-\left(A-c_{m}\right) e_{r} e_{m}\right]+e_{m}^{2} \gamma\left[\beta \gamma\left(\theta A-c_{r}\right)+(\beta g+\alpha)\right]}{2\left[\beta \gamma^{2}\left(e_{r}^{2}-2 \theta e_{r} e_{m}+\theta e_{m}^{2}\right)+e_{m}^{2}\right]},
\end{array}\right.
$$


When $M_{m}+M_{r} \geq q_{2 m} e_{m}+q_{2 r} e_{r}$, the profit function is described as a piece of curved surface with apex $A_{4}\left(q_{2 m}^{c}, q_{2 r}^{c}, \prod_{s \mid\left(q_{2 m}=q_{2 m}^{\prime}, q_{2 r}=q_{2 r}^{c}\right)}\right)$; we note this surface as S1; when $M_{m}+M_{r}<q_{2 m} e_{m}+q_{2 r} e_{r}$, the profit function is described as a piece of curved surface with apex $B_{4}\left(q_{2 m}^{c^{\prime \prime}}, q_{2 r}^{c^{\prime \prime}}, \prod_{s \mid\left(q_{2 m}=q_{2 m}^{c^{\prime \prime}}, q_{2 r}=q_{2 r}^{c^{\prime \prime}}\right)}\right)$; we note this surface as S2. Since we assume $\varepsilon_{1}<\varepsilon_{2}$, then $q_{2 m}^{c}>q_{2 m}^{c^{\prime \prime}}$ and $q_{2 r}^{c}<q_{2 r}^{c^{\prime \prime}}$, i.e., $q_{2 m}^{c} e_{m}+q_{2 r}^{c} e_{r}>q_{2 m}^{c^{\prime \prime}} e_{m}+q_{2 r}^{c^{\prime \prime}} e_{r}$. There are three cases depending on the relationship among $\left(q_{2 m}^{c} e_{m}+q_{2 r}^{c} e_{r}\right)$, $\left(q_{2 m}^{c^{\prime \prime}} e_{m}+q_{2 r}^{c^{\prime \prime}} e_{r}\right)$, and $\left(M_{m}+M_{r}\right)$.

(i) When $\quad M_{m}+M_{r}<q_{2 m}^{c^{\prime \prime}} e_{m}+q_{2 r}^{c^{\prime \prime}} e_{r}, \quad \max \prod_{s}=$ $\left\{\begin{array}{l}\prod_{s \mid\left(q_{2 m}=q_{2 m}^{q^{\prime \prime}}, q_{2 r}=q_{2 r}^{q^{\prime \prime}}\right)} \quad M_{m}+M_{r}<q_{2 m} e_{m}+q_{2 r} e_{r} \\ \prod_{s \mid\left(q_{2 m}=q_{2 m}^{q^{\prime \prime}}, q_{2 r}=q_{2 r}^{q^{\prime \prime}}\right)}\end{array}\right.$

$M_{m}+M_{r} \geq q_{2 m} e_{m}+q_{2 r} e_{r}$.

$\prod_{s \mid\left(q_{2 m}=q_{2 m}^{c^{\prime \prime}}, q_{2 r}=q_{2 r}^{c^{\prime \prime}}\right)}>\prod_{s \mid\left(q_{2 m}=q_{2 m}^{c^{t,}}, q_{2 r}=q_{2 r}^{c^{b}}\right)}$

Since $q_{2 m}^{* *}=q_{2 m}^{c^{\prime \prime}}, q_{2 r}^{* *}=q_{2 r}^{c^{\prime \prime}}$.

(ii) When $q_{2 m}^{c^{\prime \prime}} e_{m}+q_{2 r}^{c^{\prime \prime}} e_{r}<M_{m}+M_{r}<q_{2 m}^{c} e_{m}+q_{2 r}^{c} e_{r}$, $\max \prod_{s}=\prod_{s \mid\left(q_{2 m}=q_{2 m}^{t_{2}^{\prime \prime}}, q_{2 r}=q_{2 r}^{c^{\prime \prime}}\right)}$ Therefore, $q_{2 m}^{* *}=q_{2 m}^{c^{\prime \prime}}, q_{2 r}^{* *}=q_{2 r}^{c^{\prime \prime}}$.

(iii) When

$$
M_{m}+M_{r}>q_{2 m}^{c} e_{m}+q_{2 r}^{c} e_{r}
$$

$\max \prod_{s}=$

$$
\begin{array}{ll}
\left\{\prod_{s \mid\left(q_{2 m}=q_{2 m}^{q^{\prime \prime}}, q_{2 r}=q_{2 r}^{c^{\prime \prime}}\right)} \quad M_{m}+M_{r}<q_{2 m} e_{m}+q_{2 r} e_{r}\right. \\
\prod_{s \mid\left(q_{2 m}=q_{2 m}^{c}, q_{2 r}=q_{2 r}^{c}\right)} & \text { Since } \\
M_{m}+M_{r} \geq q_{2 m} e_{m}+q_{2 r} e_{r} . & \text { then } \\
\prod_{s\left(q_{2 m}=q_{2 m}^{c}, q_{2 r}=q_{2 r}^{c}\right)}>\prod_{2 m \mid\left(q_{2 m}=q_{2 m}^{c^{\prime \prime}}, q_{2 r}=q_{2 r}^{c^{\prime \prime}}\right)}, & \\
q_{2 m}^{* *}=q_{2 m}^{c}, q_{2 r}^{* *}=q_{2 r}^{c} . &
\end{array}
$$

The optimal decisions are summarized as follows:

$$
q_{2 m}^{* *}= \begin{cases}q_{2 m}^{c^{\prime \prime}}, & \left(M_{m}+M_{r}\right) \leq\left(q_{2 m}^{c^{\prime \prime}} e_{m}+q_{2 r}^{c^{\prime \prime}} e_{r}\right), \\ q_{2 m}^{c^{\prime \prime}}, & q_{2 m}^{c^{\prime \prime}} e_{m}+q_{2 r}^{c^{\prime \prime}} e_{r}<M_{m}+M_{r}<q_{2 m}^{c} e_{m}+q_{2 r}^{c} e_{r}, \\ q_{2 m}^{c}, & \left(M_{m}+M_{r}\right) \geq\left(q_{2 m}^{c^{\prime \prime}} e_{m}+q_{2 r}^{c^{\prime \prime}} e_{r}\right),\end{cases}
$$

$$
q_{2 r}^{* *}= \begin{cases}q_{2 r}^{c^{\prime \prime}}, & \left(M_{m}+M_{r}\right) \leq\left(q_{2 m}^{c^{\prime \prime}} e_{m}+q_{2 r}^{c^{\prime \prime}} e_{r}\right), \\ q_{2 r}^{c^{\prime \prime}}, & q_{2 m}^{c^{\prime \prime}} e_{m}+q_{2 r}^{c^{\prime \prime}} e_{r}<M_{m}+M_{r}<q_{2 m}^{c} e_{m}+q_{2 r}^{c} e_{r}, \\ q_{2 r}^{c}, & \left(M_{m}+M_{r}\right) \geq\left(q_{2 m}^{c^{\prime \prime}} e_{m}+q_{2 r}^{c^{\prime \prime}} e_{r}\right) .\end{cases}
$$

$$
\text { Let } \quad B^{c}= \begin{cases}\varepsilon_{1} e_{m}, & M_{m}+M_{r}>q_{2 m}^{c} e_{m}+q_{2 r}^{c} e_{r}, \\ \varepsilon_{2} e_{m}, & M_{m}+M_{r}<q_{2 m}^{c^{\prime \prime}} e_{m}+q_{2 r}^{c^{\prime}} e_{r},\end{cases}
$$

$C^{c}=\left\{\begin{array}{ll}\varepsilon_{1}\left(\theta e_{m}-e_{r}\right), & M_{m}+M_{r}>q_{2 m}^{c} e_{m}+q_{2 r}^{c} e_{r}, \\ \varepsilon_{2}\left(\theta e_{m}-e_{r}\right), & M_{m}+M_{r}<q_{2 m}^{c^{\prime \prime}} e_{m}+q_{2 r}^{c^{\prime}} e_{r},\end{array}\right.$ and we

can obtain equations (27) and (28).

By substituting equations (27) and (28) into equations (2)-(4), we obtain equations (29)-(32).

\section{Data Availability}

The data used to support the findings of this study are included within the article.

\section{Conflicts of Interest}

The authors declare that there are no conflicts of interest regarding the publication of this article.

\section{Acknowledgments}

This study was supported by the National Natural Science Foundation of China with Research Fund Nos. 71501046 and 71971064, China Postdoctoral Science Foundation under Grant Nos. 2017M612019, 2016M602053, and 2018T110640, National Natural Science Foundation of Fujian Province with Research Fund No. 2019J01636, Program for New Century Excellent Talents in Fujian Province University, Program of Cultivating Outstanding Young Scientific Research Talents in Fujian Province University, "Qishan Scholars" Award Program of Fuzhou University, and Talent Introduction Fund Project of Fuzhou University.

\section{References}

[1] J. Song and M. Leng, "Analysis of the single-period problem under carbon emissions policies," in Handbook of Newsvendor Problems, pp. 297-313, Springer, New York, NY, USA, 2012.

[2] X. Shi and H. Meier, "Carbon emission assessment to support planning and operation of low-carbon production systems," Procedia CIRP, vol. 3, pp. 329-334, 2012.

[3] S. Webster and S. Mitra, "Competitive strategy in remanufacturing and the impact of take-back laws," Journal of Operations Management, vol. 25, no. 6, pp. 1123-1140, 2007.

[4] M. D.-A. Abdulrahman, N. Subramanian, C. Liu, and C. Shu, "Viability of remanufacturing practice: a strategic decision making framework for Chinese auto-parts companies," Journal of Cleaner Production, vol. 105, pp. 311-323, 2015.

[5] Z. Jiang, T. Zhou, H. Zhang, Y. Wang, H. Cao, and G. Tian, "Reliability and cost optimization for remanufacturing process planning," Journal of Cleaner Production, vol. 135, pp. 1602-1610, 2016.

[6] V. M. Smith and G. A. Keoleian, "The value of remanufactured engines: life-cycle environmental and economic perspectives," Journal of Industrial Ecology, vol. 8, no. 1-2, pp. 193-221, 2004.

[7] J. Tian and M. Chen, "Sustainable design for automotive products: dismantling and recycling of end-of-life vehicles," Waste Management, vol. 34, no. 2, pp. 458-467, 2014.

[8] A. Örsdemir, E. Kemahlığlu-Ziya, and A. K. Parlaktürk, "Competitive quality choice and remanufacturing," Production and Operations Management, vol. 23, no. 1, pp. 48-64, 2014.

[9] K. Wang, Y. Zhao, Y. Cheng, and T.-M. Choi, "Cooperation or competition? Channel choice for a remanufacturing fashion supply chain with government subsidy," Sustainability, vol. 6, no. 10, pp. 7292-7310, 2014.

[10] Z.-B. Zou, J.-J. Wang, G.-S. Deng, and H. Chen, “Third-party remanufacturing mode selection: outsourcing or authorization?" Transportation Research Part E: Logistics and Transportation Review, vol. 87, pp. 1-19, 2016. 
[11] P. Majumder and H. Groenevelt, "Competition in remanufacturing," Production and Operations Management, vol. 10, no. 2, pp. 125-141, 2001.

[12] Q. Bai and M. Chen, "The distributionally robust newsvendor problem with dual sourcing under carbon tax and cap-andtrade regulations," Computers \& Industrial Engineering, vol. 98, pp. 260-274, 2016.

[13] M. E. Ferguson and L. B. Toktay, "The effect of competition on recovery strategies," Production and Operations Management, vol. 15, no. 3, pp. 351-368, 2006.

[14] O. Kaya, "Incentive and production decisions for remanufacturing operations," European Journal of Operational Research, vol. 201, no. 2, pp. 442-453, 2010.

[15] G. Ferrer and J. M. Swaminathan, "Managing new and remanufactured products," Management Science, vol. 52, no. 1, pp. 15-26, 2006.

[16] J. Wei and J. Zhao, "Pricing and remanufacturing decisions in two competing supply chains," International Journal of Production Research, vol. 53, no. 1, pp. 258-278, 2015.

[17] S. Mitra and S. Webster, "Competition in remanufacturing and the effects of government subsidies," International Journal of Production Economics, vol. 111, no. 2, pp. 287-298, 2008.

[18] C.-H. Wu, "Strategic and operational decisions under sales competition and collection competition for end-of-use products in remanufacturing," International Journal of Production Economics, vol. 169, pp. 11-20, 2015.

[19] X. Zhu, M. Wang, G. Chen, and X. Chen, "The effect of implementing trade-in strategy on duopoly competition," European Journal of Operational Research, vol. 248, no. 3, pp. 856-868, 2016.

[20] X. Hong, K. Govindan, L. Xu, and P. Du, "Quantity and collection decisions in a closed-loop supply chain with technology licensing," European Journal of Operational Research, vol. 256, no. 3, pp. 820-829, 2017.

[21] J.-W. Ho, Y.-S. Huang, and C.-L. Hsu, "Pricing under internal and external competition for remanufacturing firms with green consumers," Journal of Cleaner Production, vol. 202, pp. 150-159, 2018.

[22] L. Xu and C. Wang, "Sustainable manufacturing in a closedloop supply chain considering emission reduction and remanufacturing," Resources, Conservation and Recycling, vol. 131, pp. 297-304, 2018.

[23] L. Zhou and S. M. Gupta, "Marketing research and life cycle pricing strategies for new and remanufactured products," Journal of Remanufacturing, vol. 9, no. 1, pp. 29-50, 2019.

[24] B. Liao, "Warranty as a competitive dimension for remanufactured products under stochastic demand," Journal of Cleaner Production, vol. 198, pp. 511-519, 2018.

[25] Z. Liu, C. Diallo, J. Chen, and M. Zhang, "Optimal pricing and production strategies for new and remanufactured products under a non-renewing free replacement warranty," International Journal of Production Economics, vol. 10, 2019.

[26] X. Sun, Y. Zhou, Y. Li, K. Govindan, and X. Han, "Differentiation competition between new and remanufactured products considering third-party remanufacturing," Journal of the Operational Research Society, vol. 71, no. 1, pp. 161-180, 2020.

[27] H. Zhang, X. Wang, P. Qing, and X. Hong, “Optimal licensing of uncertain patents in a differentiated Stackelberg duopolistic competition market," International Review of Economics \& Finance, vol. 45, pp. 215-229, 2016.
[28] W. Zhang, Z. Hua, Y. Xia, and B. Huo, "Dynamic multitechnology production-inventory problem with emissions trading," IIE Transactions, vol. 48, no. 2, pp. 110-119, 2016.

[29] M. S. Hashiguchi, "Recycling efforts and patent rights protection in the United States and Japan," Columbia Journal of Environmental Law, vol. 33, pp. 169-179, 2008.

[30] Y. Huang and Z. Wang, "Demand disruptions, pricing and production decisions in a closed-loop supply chain with technology licensing," Journal of Cleaner Production, vol. 191, pp. 248-260, 2018.

[31] N. Oraiopoulos, M. E. Ferguson, and L. B. Toktay, "Relicensing as a secondary market strategy," Management Science, vol. 58, no. 5, pp. 1022-1037, 2012.

[32] D. Zhang, X. Zhang, B. Shi, J. Cao, and G. Zhou, "Collection and remanufacturing of waste products under patent protection and government regulation," Sustainability, vol. 10, no. 5, p. 1402, 2018.

[33] Y. Huang and Z. Wang, "Pricing and production decisions in a closed-loop supply chain considering strategic consumers and technology licensing," International Journal of Production Research, vol. 57, no. 9, pp. 2847-2866, 2019.

[34] J. Zhao, C. Wang, and L. Xu, "Decision for pricing, service, and recycling of closed-loop supply chains considering different remanufacturing roles and technology authorizations," Computers \& Industrial Engineering, vol. 132, pp. 59-73, 2019.

[35] X. Gong and S. X. Zhou, "Optimal production planning with emissions trading," Operations Research, vol. 61, no. 4, pp. 908-924, 2013.

[36] A. Yenipazarli, "Managing new and remanufactured products to mitigate environmental damage under emissions regulation," European Journal of Operational Research, vol. 249, no. 1, pp. 117-130, 2016.

[37] K. Cao, P. He, and Z. Liu, "Production and pricing decisions in a dual-channel supply chain under remanufacturing subsidy policy and carbon tax policy," Journal of the Operational Research Society, vol. 24, pp. 1-17, 2019.

[38] K. Cao, B. Xu, and J. Wang, "Optimal trade-in and warranty period strategies for new and remanufactured products under carbon tax policy," International Journal of Production Research, vol. 58, no. 1, pp. 180-199, 2020.

[39] X. Chang, H. Xia, H. Zhu, T. Fan, and H. Zhao, "Production decisions in a hybrid manufacturing-remanufacturing system with carbon cap and trade mechanism," International Journal of Production Economics, vol. 162, pp. 160-173, 2015.

[40] Y. Wang, W. Chen, and B. Liu, "Manufacturing/remanufacturing decisions for a capital-constrained manufacturer considering carbon emission cap and trade," Journal of Cleaner Production, vol. 140, pp. 1118-1128, 2017.

[41] Z. Miao, H. Mao, K. Fu, and Y. Wang, "Remanufacturing with trade-ins under carbon regulations," Computers \& Operations Research, vol. 89, pp. 253-268, 2018.

[42] Z. Zhang, B. Gong, J. Tang, Z. Liu, and X. Zheng, "The joint dynamic green innovation and pricing strategies for a hybrid system of manufacturing and remanufacturing with carbon emission constraints," Kybernetes, vol. 48, no. 8, pp. 16991730, 2019.

[43] B. Liu, M. Holmbom, A. Segerstedt, and W. Chen, "Effects of carbon emission regulations on remanufacturing decisions with limited information of demand distribution," International Journal of Production Research, vol. 53, no. 2, pp. 532-548, 2015.

[44] T. Shu, Q. Wu, S. Chen, S. Wang, K. K. Lai, and H. Yang, "Manufacturers'/remanufacturers' inventory control 
strategies with cap-and-trade regulation," Journal of Cleaner Production, vol. 159, pp. 11-25, 2017.

[45] G. Dou, H. Guo, Q. Zhang, and X. Li, "A two-period carbon tax regulation for manufacturing and remanufacturing production planning," Computers \& Industrial Engineering, vol. 128, pp. 502-513, 2019. 